High dielectric constant conjugated materials for organic photovoltaics Peer-reviewed author version

BREBELS, Jeroen; MANCA, Jean; LUTSEN, Laurence; VANDERZANDE, Dirk \& MAES, Wouter (2017) High dielectric constant conjugated materials for organic photovoltaics. In: JOURNAL OF MATERIALS CHEMISTRY A, 5(46), p. 24037-24050.

DOI: $10.1039 / \mathrm{cta06808e}$

Handle: http://hdl.handle.net/1942/25559 


\section{High dielectric constant conjugated materials for organic photovoltaics}

Jeroen Brebels, ${ }^{a}$ Jean V. Manca, ${ }^{b}$ Laurence Lutsen, ${ }^{c}$ Dirk Vanderzande, ${ }^{a, c}$ and Wouter Maes*a,c

(a) UHasselt - Hasselt University, Institute for Materials Research (IMO-IMOMEC), Design \& Synthesis of Organic Semiconductors (DSOS), Agoralaan 1 - WET/OBPC, 3590 Diepenbeek, Belgium

(b) UHasselt - Hasselt University, X-LAB, Agoralaan, 3590 Diepenbeek, Belgium

(c) IMEC, IMOMEC Associated Laboratory, Wetenschapspark 1, 3590 Diepenbeek, Belgium

Corresponding author: Tel.: +32 11268312; E-mail: wouter.maes@uhasselt.be 


\begin{abstract}
Organic photovoltaics (OPV) offer a low-cost and esthetically appealing thin-film alternative to the well-known silicon-based solar panels, opening up new applications and markets. A substantial increase in power conversion efficiency (to over 13\%) has been achieved for these organic solar cells over the last decade, largely as a result of intensive research on novel electron donor and acceptor materials, combined in a bulk heterojunction device structure. Nevertheless, it is clear that further progress is required to be competitive with more efficient traditional and other emerging thin-film PV technologies. At this moment, the device performance is (among others) limited by the low dielectric constants $\left(\varepsilon_{r}=\sim 3-4\right)$ of the state of the art photoactive organic materials. Important loss processes inherently connected to the strong Coulombic interactions within low-permittivity organic materials can be suppressed through the enhancement of $\varepsilon_{r}$. High dielectric constant materials show lower exciton binding energies and hence recombination can be reduced, improving the charge carrier extraction efficiency. Despite these promising prospects, limited research has been devoted to the development and OPV integration of high-dielectric organic semiconductors. In here, an overview is provided of the approaches applied so far to enhance $\varepsilon_{r}$ of organic compounds specifically developed for OPV purposes, commenting on the insights obtained and the challenges remaining.
\end{abstract}




\section{Introduction}

Organic photovoltaics (OPV) have gained a lot of attention over the past 20 years as a result of their superior characteristics to produce light-weight, fully flexible and esthetically pleasing (colored) devices at reduced manufacturing costs. ${ }^{1-4}$ Their thin-film character, ease of production by printing techniques and the employment of abundant, non-toxic organic photoactive materials render organic solar cells an attractive low-cost, complementary PV technology, enabling to target new markets such as building or automotive integration and numerous indoor and outdoor applications. ${ }^{5-8}$ Over the years, OPV research has mainly focused on the quest for suitable electron donor and acceptor molecules, either of polymer or small molecule nature, which has resulted in organic solar cells with power conversion efficiencies (PCE's) exceeding 13\%. ${ }^{9-12}$ A major limitation of organic semiconductors is their restricted exciton (i.e. hole-electron pair) lifetime of $\sim 1 \mathrm{~ns}$ and exciton diffusion length of $\sim 10$ $\mathrm{nm} .{ }^{13}$ The photo-generated holes and electrons experience a strong Coulombic interaction due to the low relative permittivity values in organic semiconductors $\left(\varepsilon_{r}=\sim 3-4\right)$, which lead to significant recombination losses. ${ }^{14}$ The limited exciton dissociation rate particularly restrains the photocurrent generation and fill factor (FF) of organic solar cells. To overcome these strong Coulombic interactions, a second semiconducting material in close proximity is required, with a different electron affinity or ionization potential to trigger the exciton dissociation, i.e. electron transfer from an electron donor material to an electron acceptor and hole transfer in the opposite direction. In 1991, Yokoyama et al. introduced the bulk heterojunction (BHJ) concept. ${ }^{15}$ Co-evaporation of two dyes offered a strongly increased interfacial area to improve exciton dissociation as compared to the bilayer concept used before. The groups of Heeger and Holmes successfully applied this concept in polymer solar cells in 1995 (Figure 1a)..$^{16,17}$ However, a very specific nanostructured photoactive layer morphology is required to overcome the limited exciton diffusion length, which is far from trivial to achieve and to reproduce. ${ }^{18}$ The solvent (and possible co-solvent) used to deposit the photoactive layer has a major influence on the final BHJ film morphology, A wide range of organic solvents (e.g. chloroform, (ortho-di)chlorobenzene, 1.1.2.2-tetrachloroethane) and co-solvents (e.g. 1.8-diiodooctane, 1-chloronaphthalene) have been used to optimize the active layer morphology, traditionally done in a trial and error fashion. With the aid of cosolvents, favorable morphologies can be pursued as their higher boiling point allows to optimize the crystallization time given to a certain material. ${ }^{19}$

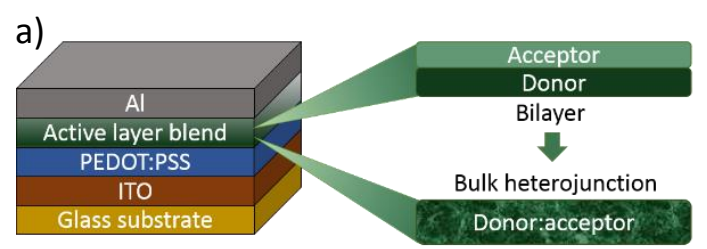




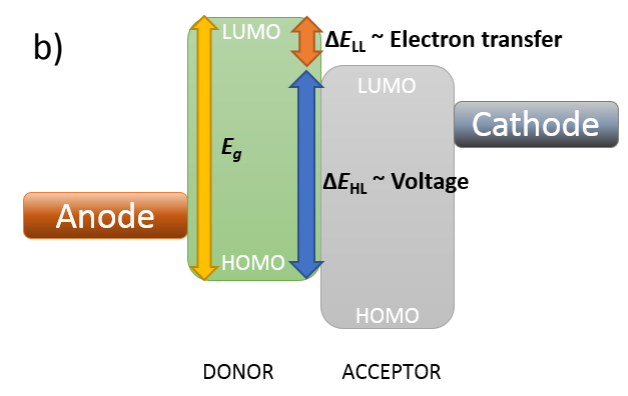

Figure 1. a) Illustration of a standard organic solar cell stack with either a bilayer or a bulk heterojunction donor:acceptor photoactive layer; b) Schematic energy level diagram of a bulk heterojunction organic solar cell (omitting the interlayers).

A major advantage of OPV over competing technologies is the fact that the molecular structures of the photoactive organic materials can be readily fine-tuned to achieve optimally balanced energy levels (Figure 1b). The introduction of electron withdrawing substituents will for instance lower the LUMO (lowest unoccupied molecular orbital) level of the electron donor material, but the energy offset with the LUMO of the electron acceptor ( $\Delta E_{\mathrm{LL}}$ ) will also be reduced, which can be detrimental for the exciton dissociation. On the other hand, introducing more electron rich structures will push up the HOMO (highest occupied molecular orbital) level of the electron donor material, resulting in a lower bandgap $\left(E_{\mathrm{g}}\right)$ and hence affecting the light-harvesting potential. However, since the open-circuit voltage $\left(V_{o c}\right)$ is proportional to the difference between the HOMO level of the electron donor and the LUMO level of the electron acceptor $\left(\Delta E_{\mathrm{HL}}\right)$, it will drop and hence the efficiency of the OPV device decreases. As a result, a balance should be found between efficient light harvesting, a high $V_{o c}$ and a sufficiently high LUMO offset. Moreover, an appropriate solubility and miscibility of the organic semiconducting materials can be targeted by dedicated structural (side chain) variations to achieve a near-ideal, 'intimately mixed' nanostructured BHJ active layer. In 2006, Scharber and co-workers defined a set of design rules for electron donor molecules in $\mathrm{BHJ}$ organic solar cells (in combination with fullerene acceptors). ${ }^{20} \mathrm{It}$ was speculated that, if the desired material properties could be achieved, this would allow to reach the (at that time very ambitious) $10 \%$ efficiency limit. These molecular design rules have steadily been refined over the years, but essentially the same guidelines were always used as a basis for material development. ${ }^{21,22}$

In 2012, Hummelen et al. outlined three different pathways to a novel efficiency regime for organic solar cells, with PCE's in excess of $20 \%:{ }^{23}$ i) a radiation limit was presented that clarifies the role of charge transfer (CT) absorption (which should be sufficiently weak), ii) a model based on exciton generation in both the electron donor and acceptor material was used to demonstrate how reduction of the reorganization energies can result in a significant improvement in $\mathrm{PCE}$, and iii) the dielectric constant $\left(\varepsilon_{\mathrm{r}}\right)$ was put forward as a crucial parameter for high-efficiency organic solar cells, reducing relaxation and recombination processes. In 2009, Kirchartz et al. presented that among all loss mechanisms occurring in OPV, singlet exciton recombination accounts for almost $12 \%$ and charge transfer exciton recombination causes an efficiency loss of more than $32 \%$, both because of the rather low relative permittivity values of organic semiconductors. ${ }^{24}$ Inorganic semiconductors typically have dielectric constants in the range of 10-15, which results in a weak Coulombic interaction (i.e. Wannier-Mott type excitons are created, extending over multiple molecules). ${ }^{25}$ These values 
are considerably higher than those of their organic counterparts $(\sim 3-4)$, wherein a tightly bound electron-hole pair (i.e. a Frenkel exciton on an individual molecule) is formed upon the absorption of light. ${ }^{25}$ Organic materials therefore have much higher exciton binding energies $\left(E_{\mathrm{b}} ; 0.3-1.0 \mathrm{eV}\right)$, as these are directly related to the intrinsic dielectric properties via

$$
E_{b}=\frac{e^{2}}{4 \pi \varepsilon_{r} \varepsilon_{0} r}
$$

where $e$ is the elementary charge, $\varepsilon_{0}$ is the permittivity of vacuum, $\varepsilon_{\mathrm{r}}$ is the relative permittivity of the material, and $r$ is the distance between the electron and hole. ${ }^{26}$ When dielectric constants in the same range as silicon ( $\sim 11)$ could be achieved for organic materials, thicker active layers could be used, harvesting more of the incoming light and beneficial for roll-toroll processing, and even single junction devices could be prepared (as no $\Delta E_{\mathrm{LL}}$ is required anymore to efficiently separate the hole and electron; Figure $1 \mathrm{~b}$ ), overruling all morphological issues $\mathrm{BHJ}$ organic solar cells are facing to date. ${ }^{23,27,28} \mathrm{~A}$ recent study on the combined influence of charge mobility and the dielectric constant for instance showed that higher efficiencies could be achieved with lower optimum mobilities of the charge carriers when a suitable active layer blend with a high $\varepsilon_{r}$ of around 8 could be designed. ${ }^{29}$

The dielectric constant (i.e. static relative permittivity) is defined as the ratio of the relative permittivity of the material divided by the permittivity of free space. In practical terms, it represents the capacity of a material to store electrical energy under an applied electric field relative to vacuum, in which a part of the electrical energy is used to polarize the organic material. In this respect, the dielectric constant is directly correlated to the polarizability and the ability of organic compounds to polarize in the presence of an applied electric field. Consequently, synthetic approaches to increase $\varepsilon_{r}$ are mainly focusing on local changes on the conjugated backbone and/or periphery via the introduction of polar or polarizable substituents. ${ }^{29-31} \mathrm{~A}$ beneficial side effect of this strategy is the fact that the resulting materials become more hydrophilic, which helps to reduce the environmental impact of the OPV production process. ${ }^{32-34}$ At present, the active layer of the top-efficiency $\mathrm{BHJ}$ organic solar cells, combining a low bandgap electron donor (polymer or small molecule) and a fullerene (or alternative) acceptor in the photoactive layer blend, is most often deposited from solutions of high-boiling chlorinated solvents such as (di)chlorobenzene. ${ }^{12,35}$ To reduce the ecological footprint, processing from less harmful solvents (e.g. alcohols and ultimately water) is highly desirable. ${ }^{11,36,37}$ High-permittivity hydrophilic organic materials hence have great potential for OPV applications.

Different techniques can be used to measure the dielectric constants of organic compounds, but impedance spectroscopy (IS) and charge extraction by linearly increasing voltage (CELIV) are the most commonly used methods. One of the most convenient approaches is to use a standard OPV device architecture (ITO/PEDOT:PSS/organic material/AI) to measure the capacitance of a parallel plate capacitor,

$$
C=\frac{\varepsilon_{r} \varepsilon_{0} A}{d}
$$

where $C$ is the capacitance of the sample, $A$ is the capacitor's size defined by the electrode, $d$ is the thickness of the organic layer, $\varepsilon_{0}$ is the permittivity of vacuum, and $\varepsilon_{\mathrm{r}}$ is the relative dielectric constant of the organic material. The capacitance of the device is normally measured 
in the $\mathrm{Hz}$ to $\mathrm{MHz}$ (or even $\mathrm{GHz}$ ) regime because bimolecular recombination is reversely proportional to the relative permittivity and occurs on a $\mu$ s timescale. ${ }^{30}$ Therefore, a relatively constant $\varepsilon_{r}$ up to the $\mathrm{MHz}$ (or even $\mathrm{GHz}$ ) range is required when materials are applied in $\mathrm{BHJ}$ OPV layers. From equation 2, it is clear that the thickness of the dielectric material is very important and the active layer should be very smooth to get reliable results. To minimize the error on the measurement, PEDOT:PSS is used as an intermediate layer to reduce the surface roughness of the underlying ITO layer in order to achieve a smoother and more evenly distributed active layer. It is often also better to use thicker active layers (in the range of $100-200 \mathrm{~nm}$ ) to minimalize the errors made in these measurements.

\section{Strategies toward increased dielectric constants in OPV materials}

If one desires to increase the dielectric constant (which is per definition a bulk property) of a conjugated polymer, small molecule or fullerene by local structural changes, several strategies can be adopted. The structural variations can involve either the backbone of the periphery/side chain pattern. The mobile (freely rotating) alkyl side chains are attractive targets for effective screening of the dissociated hole/electron pair formed upon light absorption by the photoactive material. In the sections below, the different strategies used so far to increase $\varepsilon_{r}$ are introduced in a stepwise manner. We will first focus on the electron donor materials and then move on to the electron acceptor materials. Finally, a completely different strategy is discussed, wherein high dielectric constant (in)organic dopants are added to the photoactive layer blend.

\subsection{High- $\varepsilon_{r}$ organic donor materials}

Push-pull low bandgap copolymers and related small molecules comprising of electrondonating and electron-accepting building blocks in an alternating fashion are currently the state of the art electron donor materials for BHJ OPV devices. ${ }^{9,10} \mathrm{~A}$ lot of material optimization with respect to absorption, bandgap, energy levels, solubility, etc., has been realized over the past decade, but little efforts have been done to enhance the dielectric properties, using only a few general strategies. The structures of all donor materials discussed in this section are depicted in Figure 2 and the $\varepsilon_{r}$ values, HOMO-LUMO energy levels, hole mobilities $\left(\mu_{\mathrm{h}}\right)$, and resulting organic solar cell output parameters are listed in Table 1. 

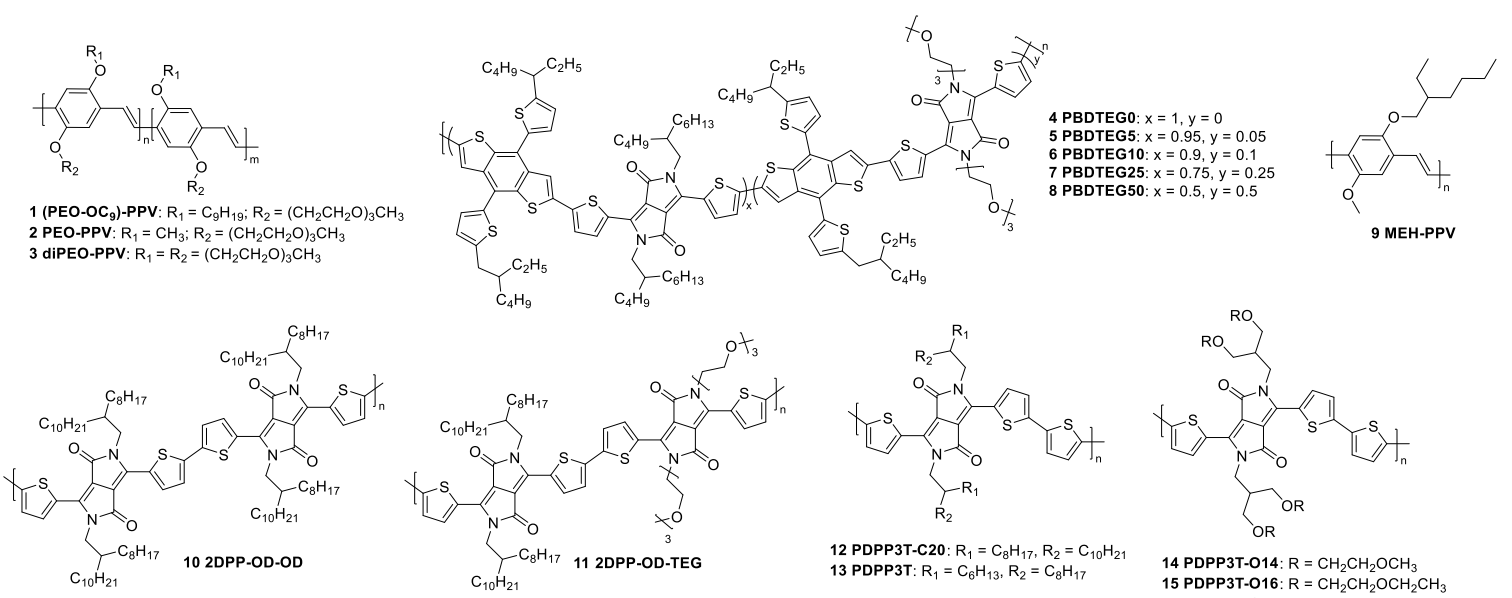

14 PDPP3T-014: $\mathrm{R}=\mathrm{CH}_{2} \mathrm{CH}_{2} \mathrm{OCH}_{3}$

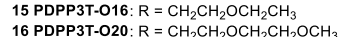
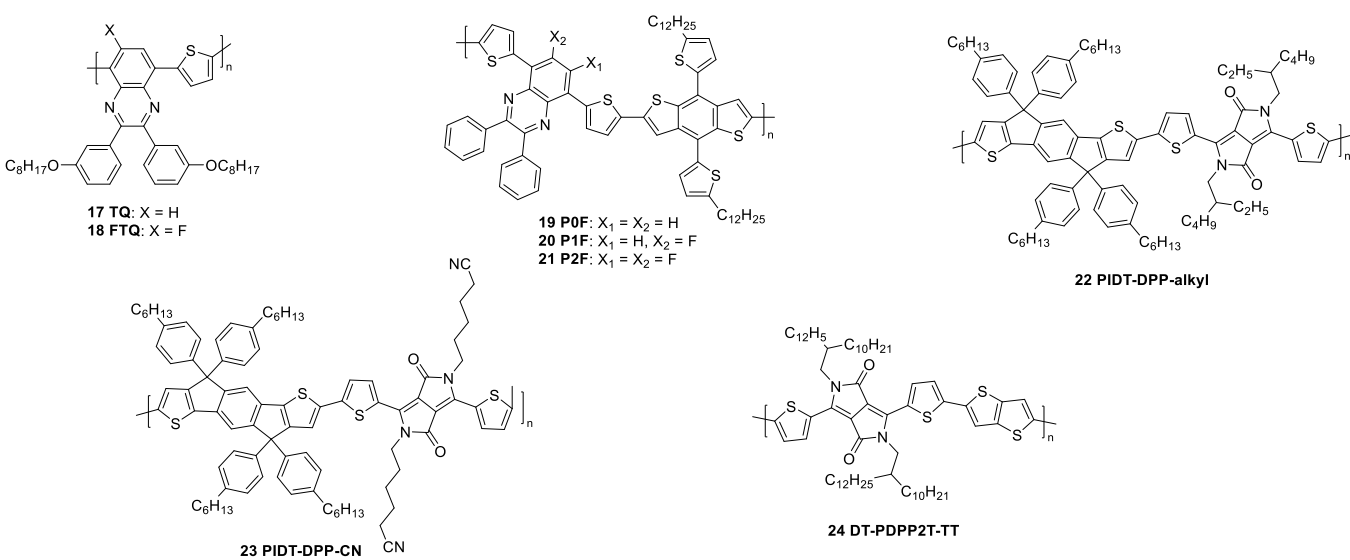

22 PIDT-DPP-alkyl

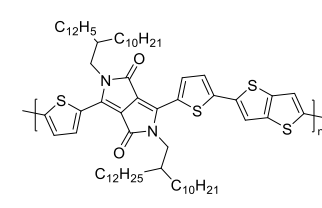

24 DT-PDPP2T-TT

Figure 2. Donor polymers employed in $\varepsilon_{r}$ studies to improve the performance of organic solar cells.

Table 1. Dielectric constants, HOMO-LUMO values, and hole mobilities for donor materials employed in $\varepsilon_{r}$ studies and photovoltaic parameters of the resulting BHJ OPV devices.

\begin{tabular}{|c|c|c|c|c|c|c|c|c|c|c|}
\hline Compound & $\varepsilon_{r^{a}}$ & $\begin{array}{l}\text { HOMO } \\
{[\mathrm{eV}]}\end{array}$ & $\begin{array}{c}\text { LUMO } \\
{[\mathrm{eV}]}\end{array}$ & $\begin{array}{c}\mu_{\mathrm{h}}\left[\mathrm{cm}^{2}\right. \\
\left.\mathrm{V}^{-1} \mathrm{~s}^{-1}\right]\end{array}$ & $\begin{array}{l}\text { Active } \\
\text { layer } \\
\text { blend }\end{array}$ & $\begin{array}{c}J_{\mathrm{sc}} \\
{[\mathrm{mA}} \\
\left.\mathrm{cm}^{-2}\right]\end{array}$ & $\begin{array}{l}V_{\text {oc }} \\
\text { [V] }\end{array}$ & $\mathbf{F F}$ & $\begin{array}{l}\text { PCE } \\
{[\%]^{i)}}\end{array}$ & Ref \\
\hline $\begin{array}{l}\text { (PEO-OC9)- } \\
\text { PPV } 1\end{array}$ & 4.1 & - & - & $\begin{array}{l}3-6 \times \\
10^{-4 b)}\end{array}$ & $1: \mathrm{PC}_{61} \mathrm{BM}$ & 4.3 & 0.64 & 0.34 & 0.94 & [38] \\
\hline PEO-PPV 2 & 4.0 & - & - & $\begin{array}{l}1-5 \times \\
10^{-4 b)}\end{array}$ & $2: \mathrm{PC}_{61} \mathrm{BM}$ & 1.8 & 0.38 & 0.26 & 0.18 & [38] \\
\hline $\begin{array}{c}\text { diPEO-PPV } \\
\mathbf{3}\end{array}$ & 5.5 & - & - & $\begin{array}{l}1-4 \times \\
10^{-4 b)}\end{array}$ & $3: \mathrm{PC}_{61} \mathrm{BM}$ & 0.006 & 0.61 & 0.24 & 0.0009 & [38] \\
\hline PEO-PPV 2 & 4.0 & - & - & $\begin{array}{c}1.8 \times \\
\left.10^{-6} \mathrm{c}, \mathrm{d}\right)\end{array}$ & 2:PCB-EH & 1.38 & 0.67 & 0.52 & 0.5 & [39] \\
\hline PBDTEG0 4 & - & -5.32 & -3.76 & $\begin{array}{l}\sim 9.5 \times \\
\left.10^{-5} \mathrm{e}\right)\end{array}$ & $4: P C_{71} B M$ & 13.4 & 0.73 & 0.63 & $\begin{array}{c}6.2 \\
(6.1)\end{array}$ & [40] \\
\hline PBDTEG5 5 & - & -5.32 & -3.76 & $\begin{array}{l}\sim 9.5 \times \\
\left.10^{-5} \mathrm{e}\right)\end{array}$ & $5: P_{71} B M$ & 13.8 & 0.73 & 0.63 & $\begin{array}{c}6.3 \\
(6.1)\end{array}$ & [40] \\
\hline $\begin{array}{c}\text { PBDTEG10 } \\
6\end{array}$ & - & -5.31 & -3.76 & $\begin{array}{l}\sim 9.5 \times \\
\left.10^{-5} \mathrm{e}\right)\end{array}$ & $6: P C_{71} B M$ & 14.3 & 0.72 & 0.68 & $\begin{array}{l}7.0 \\
(6.8)\end{array}$ & [40] \\
\hline $\begin{array}{c}\text { PBDTEG25 } \\
7\end{array}$ & - & -5.28 & -3.78 & $\begin{array}{l}\sim 9.5 \times \\
10^{-5} \text { e) }\end{array}$ & $7: P_{71} B M$ & 10.3 & 0.70 & 0.65 & $\begin{array}{c}4.7 \\
(4.6)\end{array}$ & [40] \\
\hline $\begin{array}{c}\text { PBDTEG50 } \\
8\end{array}$ & - & -5.25 & -3.77 & $\begin{array}{l}\sim 9.5 \times \\
\left.10^{-5} \mathrm{e}\right)\end{array}$ & $8: \mathrm{PC}_{71} \mathrm{BM}$ & 8.1 & 0.68 & 0.58 & $\begin{array}{c}3.2 \\
(3.1)\end{array}$ & [40] \\
\hline MEH-PPV 9 & $3 \pm 0.1$ & - & - & $\begin{array}{l}1.4 \times \\
10^{-6 c)} \\
\end{array}$ & - & - & - & - & - & [30] \\
\hline
\end{tabular}




\begin{tabular}{|c|c|c|c|c|c|c|c|c|c|c|}
\hline PEO-PPV 2 & $6 \pm 0.1$ & - & - & - & - & - & - & - & - & [30] \\
\hline $\begin{array}{l}\text { 2DPP-OD- } \\
\text { OD } 10\end{array}$ & $\begin{array}{c}2.1 \pm \\
0.1\end{array}$ & - & - & - & - & - & - & - & - & [30] \\
\hline $\begin{array}{l}\text { 2DPP-OD- } \\
\text { TEG } 11\end{array}$ & $\begin{array}{c}4.8 \pm \\
0.1\end{array}$ & - & - & $\begin{array}{c}2 \times 10^{-4} \\
\text { c) }\end{array}$ & - & - & - & - & - & [30] \\
\hline $\begin{array}{c}\text { PDPP3T- } \\
\text { C20 } 12\end{array}$ & $\begin{array}{c}2.0 \pm \\
0.1\end{array}$ & -5.20 & -3.50 & $\begin{array}{l}1.55 \times \\
\left.10^{-3} \mathrm{c}\right)\end{array}$ & $12: \mathrm{PC}_{71} \mathrm{BM}$ & 6.45 & 0.68 & 0.68 & 3.00 & [41] \\
\hline PDPP3T 13 & - & -5.17 & -3.61 & $0.04^{b)}$ & $13: \mathrm{PC}_{71} \mathrm{BM}$ & 11.8 & 0.65 & 0.60 & 4.7 & [42] \\
\hline $\begin{array}{c}\text { PDPP3T- } \\
01414\end{array}$ & $\begin{array}{c}5.5 \pm \\
0.3\end{array}$ & -5.13 & -3.65 & $\begin{array}{l}4.14 \times \\
10^{-3 c}\end{array}$ & $14: \mathrm{PC}_{71} \mathrm{BM}$ & 16.42 & 0.50 & 0.55 & 4.52 & [41] \\
\hline $\begin{array}{c}\text { PDPP3T- } \\
01615\end{array}$ & $\begin{array}{c}4.6 \pm \\
0.2\end{array}$ & -5.09 & -3.61 & $\begin{array}{c}2.53 \times \\
10^{-3} \mathrm{cl}\end{array}$ & $15: \mathrm{PC}_{71} \mathrm{BM}$ & 14.30 & 0.57 & 0.66 & 5.37 & [41] \\
\hline $\begin{array}{c}\text { PDPP3T- } \\
02016\end{array}$ & $\begin{array}{c}4.6 \pm \\
0.2\end{array}$ & -5.21 & -3.60 & $\begin{array}{l}1.10 \times \\
10^{-3} \mathrm{cl}\end{array}$ & $16: \mathrm{PC}_{71} \mathrm{BM}$ & 4.82 & 0.56 & 0.44 & 1.20 & [41] \\
\hline TQ 17 & 4.2 & -5.36 & -3.03 & - & 17:PC ${ }_{61} B M$ & $\sim 5.0^{\mathrm{h})}$ & 0.87 & $\sim 0.60$ & $\sim 2.6$ & [44] \\
\hline FTQ 18 & 5.5 & -5.51 & -3.08 & $\begin{array}{l}2.0 \times \\
10^{-3 f f}\end{array}$ & 18: $\mathrm{PC}_{71} \mathrm{BM}$ & $\sim 6.5^{\text {h) }}$ & 0.93 & $\sim 0.53$ & 3.21 & [44] \\
\hline POF 19 & $\begin{array}{c}6.6 \\
(4.2)\end{array}$ & -4.98 & -3.18 & - & 19: $\mathrm{PC}_{61} \mathrm{BM}$ & 6.37 & 0.83 & 0.54 & - (2.9) & [47] \\
\hline P1F 20 & $\begin{array}{c}7.2 \\
(4.4)\end{array}$ & -5.07 & -3.27 & - & $20: \mathrm{PC}_{61} \mathrm{BM}$ & 6.52 & 0.87 & 0.55 & $-(3.1)$ & [47] \\
\hline P2F 21 & $\begin{array}{c}7.9 \\
(5.4)\end{array}$ & -5.08 & -3.27 & - & 21:PC $61 \mathrm{BM}$ & 6.84 & 0.91 & 0.59 & $-(3.7)$ & [47] \\
\hline $\begin{array}{c}\text { PIDT-DPP- } \\
\text { alkyl } 22\end{array}$ & 3.5 & -5.16 & -3.18 & $0.015^{b)}$ & $\begin{array}{l}\text { 22: } \mathrm{C}_{60} \\
\text { bilayer }\end{array}$ & 2.40 & 0.63 & 0.47 & $-(0.72)$ & [51] \\
\hline $\begin{array}{l}\text { PIDT-DPP- } \\
\text { CN } 23\end{array}$ & 5.0 & -5.18 & -3.23 & $0.011^{b)}$ & $\begin{array}{l}\text { 23: } \mathrm{C}_{60} \\
\text { bilayer }\end{array}$ & 3.00 & 0.71 & 0.68 & - (1.44) & [51] \\
\hline $\begin{array}{c}\text { DT-PDPP2T- } \\
\text { TT } 24\end{array}$ & $\begin{array}{c}16.7 \pm \\
0.4 \\
(7.3 \pm \\
0.75)\end{array}$ & - & - & $\begin{array}{l}1.8 \times \\
\left.10^{-3} \mathrm{~g}\right)\end{array}$ & 24:PC ${ }_{61} \mathrm{BM}$ & 9.2 & 0.71 & 0.62 & 4.0 & [53] \\
\hline
\end{tabular}

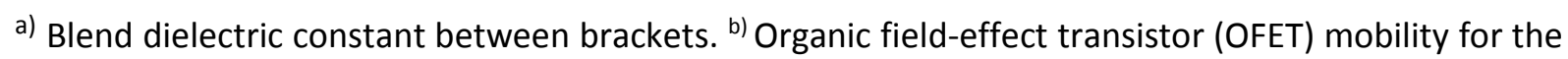
donor polymer. ${ }^{c)}$ Space-charge-limited current (SCLC) mobility for the donor polymer. ${ }^{\text {d) }}$ A hole mobility of $4 \times 10^{-7} \mathrm{~cm}^{2} \mathrm{~V}^{-1} \mathrm{~s}^{-1}$ was measured for the blend (2:PCB-EH, 1:4). e) Space-charge-limited current (SCLC) mobility of the active layer blend. ${ }^{\text {f) }}$ Organic thin-film transistor (OTFT; glass/ITO/PVP/FTQ/Ag) mobility. The hole mobility increased to $5.7 \times 10^{-3} \mathrm{~cm}^{2} \mathrm{~V}^{-1} \mathrm{~s}^{-1}$ after heating at $110^{\circ} \mathrm{C}$ for $1 \mathrm{~min}$. ${ }^{\mathrm{g})}$ Blend mobility (24: $\left.\mathrm{PC}_{61} \mathrm{BM}, 1: 3\right)$ measured by photo-CELIV. ${ }^{\text {h) }}$ Estimated values deduced from figures as no exact values were reported. ${ }^{i)}$ Best efficiency (average between brackets).

- Oligo(ethylene glycol) side chains

Initial endeavors to increase the dielectric constant of an organic semiconductor were done by Cleij et al. in 2006 by introducing oligo(ethylene glycol) (OEG) side chains on a poly( $p$ phenylene vinylene) (PPV) polymer. ${ }^{38} \mathrm{~A}$ maximum $\varepsilon_{\mathrm{r}}$ of 5.5 was achieved for diPEO-PPV 3, compared to $\varepsilon_{r}=3$ for the reference material $\mathrm{OC}_{1} \mathrm{C}_{10}-\mathrm{PPV}$ (also called MDMO-PPV), via the introduction of 2 tri(ethylene glycol) (TEG) side chains on the polymer backbone (Figure 2). The hole mobility values of the PPV-based polymers reported were all in the same range (10${ }^{4} \mathrm{~cm}^{2} / \mathrm{V} \mathrm{s}$ ) and were hardly influenced by the side chains. On the other hand, the conductivity did improve with one order of magnitude $\left(\sim 10^{-4} \mathrm{~S} / \mathrm{m}\right)$ compared to the reference MDMO-PPV. This can be attributed to the higher $\varepsilon_{r}$ values, increasing the number of charge carriers in the channel for a given voltage. Initial solar cell results were, however, rather disappointing (Table 1). Blom et al. further investigated why the efficiency was so low as compared to the standard 
PPV polymers, despite the increased dielectric constant. ${ }^{39}$ The solar cells were remade and optimized using $\mathrm{PCB}-\mathrm{EH}$ rather than $\mathrm{PC}_{61} \mathrm{BM}$ as the fullerene acceptor material (see Figure 6), aiming at a better miscibility of the donor and acceptor in the photoactive layer. However, PEO-PPV 2 (with only one TEG side chain; Figure 2) still afforded a non-optimal blend morphology, attributed to incompatible polarities of the materials in the blend, resulting in a low PCE of $0.5 \%$ (Table 1). The hole transporting features of the blend were investigated and the hole mobility turned out to be more than 3 orders of magnitude lower $\left(4 \times 10^{-7} \mathrm{~cm}^{2} \mathrm{~V}^{-1} \mathrm{~s}^{-}\right.$ $\left.{ }^{1}\right)$ as compared to a regular MDMO-PPV:PC 61 BM blend $\left(4 \times 10^{-4} \mathrm{~cm}^{2} \mathrm{~V}^{-1} \mathrm{~s}^{-1}\right)$. Thin active layer blends of only $68 \mathrm{~nm}$ afforded the maximum PCE for PEO-PPV:PCB-EH devices, with a low short-circuit current density $\left(J_{\mathrm{sc}}\right)$ of $1.38 \mathrm{~mA} \mathrm{~cm}^{-2}$ (Table 1). Further measurements were done to study the effect of the raised dielectric constant on the charge dissociation rate. Despite the lower hole mobility, an enhanced charge dissociation at short circuit and a lower decay rate were achieved as compared to the standard PPV derivatives with lower $\varepsilon_{\mathrm{r}}$ values, still showing the potential benefit of the higher relative permittivity.

Yang et al. gradually increased the amount of TEG side chains on a diketopyrrolopyrrole (DPP) based low bandgap polymer (Figure 2) to slightly enhance the polarity without too much affecting the compatibility with $\mathrm{PC}_{71} \mathrm{BM} .{ }^{40}$ The main goal of their study was to improve the photovoltaic properties by inducing a better self-assembly of the polymer chains, since OEG substituents are known to enhance the polymer-polymer interactions (vide infra). This concept was tested via a triple component random copolymerization, wherein the concentration of TEG units was gradually increased, up to a 50/50 TEG/alkyl ratio on the DPP units in copolymer 8. A PCE increase from 6.2 to $7.0 \%$ was observed for the $10 \%$ TEGDPPmodified polymer 6 , especially enhancing the $J_{s c}$ and $F F$, accompanied with a minor decrease of the $V_{\text {oc }}$ (Table 1). Further increasing the amount of TEG resulted in a strong drop of (mainly) $J_{\text {sc. }}$ Transmission electron microscopy (TEM) was used to examine the active layer morphology, which revealed that aggregation becomes stronger and a higher degree of phase separation is obtained upon increasing the density of TEG side chains on this polymer (Figure 3 ). Unfortunately, no $\varepsilon_{\mathrm{r}}$ measurements were performed in this study.
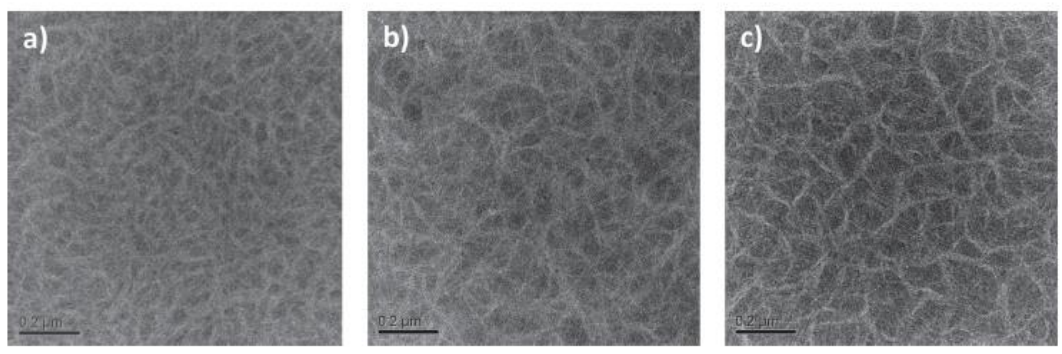

Figure 3. TEM images of a) 4:PC $\mathrm{PC}_{71} \mathrm{BM}, \mathrm{b}$ ) $6: \mathrm{PC}_{71} \mathrm{BM}$, and c) $8: \mathrm{PC}_{71} \mathrm{BM}$ blend thin films (scale bars: 200 $\mathrm{nm})$. Reproduced with permission. ${ }^{40}$ Copyright 2014, Wiley.

Hummelen, Koster and co-workers introduced OEG side chains to enhance the dielectric properties without affecting the mobilities of both charge carriers (electron and holes) and still providing good solubility in common processing solvents. ${ }^{30}$ This was also done via the substitution of the donor (or acceptor) alkyl side chains. OEG substituents have a high flexibility, with active rotations along the chain in the $\mathrm{GHz}$ frequency domain and full rotation in the $\mathrm{MHz}$ range, without sacrificing the magnitude of the dipole moment. The ease by which 
these rotations can occur directly corresponds to the dielectric constant due to a fast reorientation of the dipole moments. Experimentally, this was tested on different acceptors (fullerenes) and donors (DPP and PPV-based polymers) for BHJ organic solar cells. For the PPVbased polymer, one side chain was replaced for TEG (affording a material identical to polymer 2) as compared to the reference MEH-PPV 9 (Figure 2). An impressive doubling of the dielectric constant $\left(\varepsilon_{r}=6 \pm 0.1\right)$ was obtained by impedance spectroscopy measurements (Table 1$)$. A second, DPP-based polymer $\mathbf{1 1}$ with di(ethylene glycol) (DEG) side chains showed an increase in $\varepsilon_{\mathrm{r}}$ from $2.1 \pm 0.1$ to $4.8 \pm 0.1$ compared to the DPP polymer 10 with simple hydrocarbon side chains (Figure 2, Table 1). Very low error bars were obtained for all $\varepsilon_{\mathrm{r}}$ measurements. The authors suggest that the fast change of the dipole moments accounts for the higher $\varepsilon_{r}$ values of the OEG-functionalized materials and they illustrate that the polarization mechanism gives rise to enhanced dielectric constants rather than space-charge polarization or ionic movements. The effects on the OPV characteristics were not studied in this case.

In 2016, Wang et al. reported that the introduction of branched glycolated side chains on PDPP3T (Figure 2) results in polymers with a smaller $\pi-\pi$ stacking distance, reduced optical bandgap, higher relative permittivity and larger surface energy.$^{41}$ The hole mobilities of the different polymers did not vary that much and are all in the order of $10^{-3} \mathrm{~cm}^{2} \mathrm{~V}^{-1} \mathrm{~s}^{-1}$. The $\pi-\pi$ stacking distances as achieved from grazing incidence $X$-ray diffraction (GI-XRD) experiments were estimated to be $3.80 \AA$ for the alkylated PDPP3T-C20 reference polymer 12 and $~ 3.60 \AA$ for the glycolated polymers, which can be attributed to the faster rotations along these side chains, providing a higher chain flexibility and closer packing. This is in agreement with the UV-Vis absorption spectra, exhibiting a bathochromic shift as an indication of the stronger interactions of the glycolated backbones. The influence of the side chain substitution on the energy levels was analyzed by means of cyclic voltammetry (CV). The glycolated polymers generally displayed slightly higher HOMO energy levels and lower LUMO levels (Table 1), reducing the bandgap of the corresponding polymers. The dielectric constants of the materials as obtained by impedance spectroscopy and measured over the range from $100 \mathrm{~Hz}$ to $1 \mathrm{MHz}$ are $5.5 \pm 0.3,4.6 \pm 0.2,4.6 \pm 0.2$ and $2.0 \pm 0.1$ for polymers 14 (PDPP3T-014), 15 (PDPP3TO16), 16 (PDPP3T-O20) and 12 (PDPP3T-C20), respectively. All polymers were then also tested as donor materials for OPV devices in combination with $\mathrm{PC}_{71} \mathrm{BM}$ (Table 1). Although the highest $\varepsilon_{r}$ value was obtained for PDDP3-014 16, PDPP3T-016 15 performed best, with a maximum PCE of $5.37 \%$, outperforming both their own reference material 12 with alkyl side chains and a similar PDPP3T polymer 13 reported by Janssen et al. ${ }^{42}$ (Figure 2, Table 1). Higher short-circuit currents were obtained for the glycolated polymers, whereas the $V_{\text {oc }}$ values were somewhat lower. The main issue for the devices based on polymer $\mathbf{1 6}$ (carrying the longest $\mathrm{OEG}$ side chains) was the rough active layer morphology for the blend with $\mathrm{PC}_{71} \mathrm{BM}$ (Figure 4). This could be attributed to the higher surface energy (deduced from contact angle measurements), which reduces the compatibility with $\mathrm{PC}_{71} \mathrm{BM}$ and thereby complicates intermixing of both phases. The larger $\varepsilon_{\mathrm{r}}$ values should also reduce bimolecular recombination and this was analyzed by varying the thickness of the photoactive layer for the $14: \mathrm{PC}_{71} \mathrm{BM}$ devices from 100 to $290 \mathrm{~nm}$, maintaining PCE's in the range from 4.2-4.5\%. 

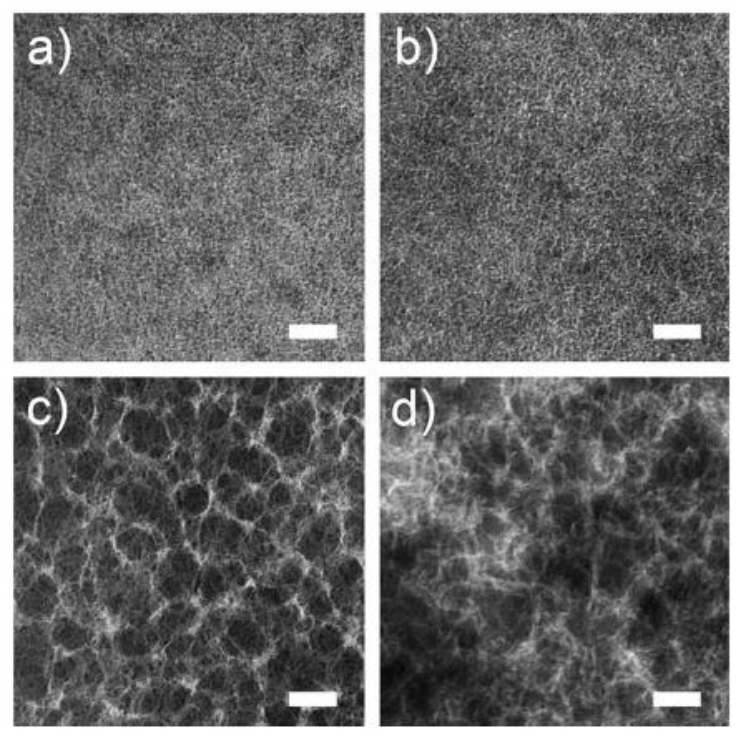

Figure 4. TEM images of the active layer blends of a) $\left.\left.14: P C_{71} B M, ~ b\right) ~ 15: P C_{71} B M, c\right) 16: P C_{71} B M$, and d) 12: $\mathrm{PC}_{71} \mathrm{BM}$ (scale bar $=200 \mathrm{~nm}$ ). Reproduced with permission. ${ }^{41}$ Copyright 2016, Wiley.

The results observed by Wang et al. for their DPP-based polymers were in accordance with previous studies from the same group wherein they already investigated the effect of replacing alkyl side chains with OEG on a benzothiadiazole-fluorene based polymer. ${ }^{43}$ For this system, it was already observed that the stacking distance in thin film decreased from 0.44 to $0.41 \mathrm{~nm}$ due to the enhanced flexibility of the side chains (Figure 5). Moreover, a red-shift in the absorption spectrum of the polymer and a higher hole mobility were observed as well. The dielectric constant was not measured in this case, but polymer solar cells were made and they showed a slightly enhanced device efficiency from $2.28 \%$ to $2.58 \%$. An alternative nonhalogenated solvent (anisole) was also used and was found to provide a better device performance $(\mathrm{PCE}=3.29 \%)$.

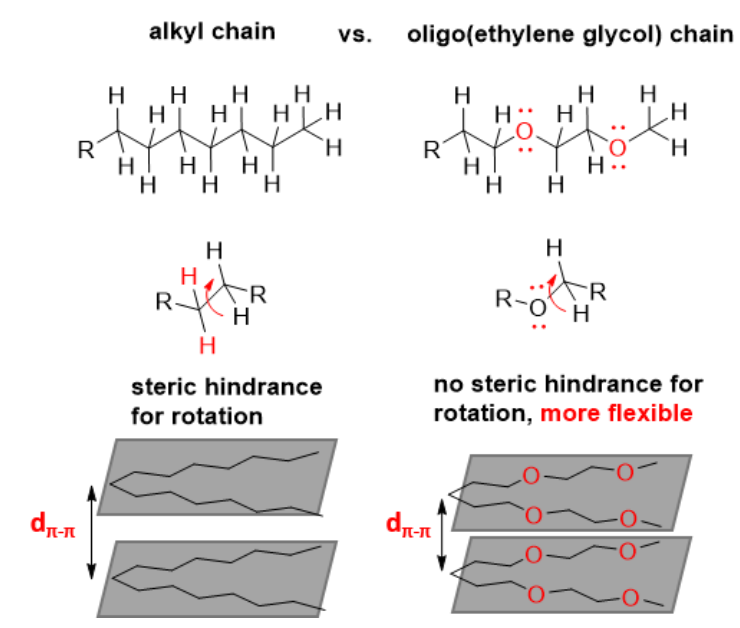

Figure 5. Schematic illustration of the superior flexibility of OEG chains (based on the Figure by Wang et $\left.a .^{43}\right)$.

\section{- Fluorination}

A second strategy to increase the dielectric constant was initially presented by Huang et al. ${ }^{44}$ They found that the introduction of fluorine directly on the polymer backbone causes an 
increase in $\varepsilon_{r}$ without sacrificing the $V_{\text {oc }}$ of the resulting OPV devices, as generally observed upon glycolation. Fluorine introduction is in fact an established approach to reduce the HOMO energy level of electron donor materials, thereby increasing the $V_{\text {oc. }}{ }^{45,46}$ In this case, fluorine was introduced on a thiophene-quinoxaline alternating copolymer (18, Figure 2). CV analysis showed that the HOMO level of the fluorinated low bandgap polymer 18 (FTQ) decreased with $0.15 \mathrm{eV}$ as compared to the TQ reference polymer 17. Fluorination also resulted in an overall increase of the OPV device efficiency, in particular due to enhanced $J_{\text {sc }}$ and $V_{\text {oc }}$ values, although the increase of the open-circuit voltage was slightly less than expected based on the CV results (Table 1). The dielectric constants were measured for both polymers, showing an $\varepsilon_{\mathrm{r}}$ of 5.5 at $10 \mathrm{kHz}$ for FTQ, higher than the non-fluorinated TQ analogue with $\varepsilon_{r}=4.2$ (Table 1).

Luscombe et al. also introduced fluorine on a quinoxaline-based polymer to investigate its effect on the $V_{\text {oc }}$ and the dielectric constant. ${ }^{47}$ To this extent, three different quinoxaline monomers (with 0, 1 and 2 fluorine atoms) were copolymerized with a benzodithiophene unit (19-21; Figure 2). CV analysis confirmed the decrease of the HOMO level when introducing 1 fluorine atom, but surprisingly no further significant decrease was observed upon the second fluorination. On the other hand, the OPV devices did show a stepwise increase in $V_{\text {oc }}$ of 0.04 $\checkmark$ for each additional fluorine atom (Table 1 ). This is not in accordance with the CV results, but the $V_{\text {oc }}$ depends on different factors, such as the binding energy of the charge transfer excitation, which is correlated to the dielectric constant (Eq. 3):

$$
V_{O C}=\frac{E_{L U M O}^{A}-E_{H O M O}^{D}-E_{b}}{q}-C
$$

where $E_{L U M O}^{A}$ is the LUMO energy level of the acceptor, $E_{\text {HOMO }}^{D}$ is the HOMO energy level of the donor, $E_{b}$ is the exciton binding energy, $q$ is the elemental electron charge, and $C$ is a constant related to illumination and temperature. ${ }^{48}$

Further analysis of the dielectric constant via impedance measurements revealed an $\varepsilon_{\mathrm{r}}$ of 6.6 for the reference polymer POF, which is remarkably high for a standard reference polymer with no polar substituents. Adding fluorine substituents to the polymer backbone further increased the $\varepsilon_{\mathrm{r}}$ with $\sim 0.6$ for each fluorine addition, moving from 6.6 to 7.2 for P1F 20 and to 7.9 for P2F 21 (Figure 2, Table 1). On the other hand, only a slight enhancement of the blend dielectric constant was observed for the addition of 1 fluorine atom (from $\varepsilon_{r}=4.2$ to 4.4), whereas the largest increase was seen for the second fluorine addition $\left(\varepsilon_{r}=5.4\right.$, Table 1$)$. This may explain the further increase of the $V_{\text {oc }}$ for P2F 21. However, a clear correlation of the dielectric constant to the enhanced device performance could not be made due to the influence of fluorine on various parameters (e.g. solubility and miscibility, active layer morphology, absorption range, etc.).

Because of the additional amount of energy required to separate excitons into free charge carriers, especially when using organic materials with high exciton binding energies, photovoltage losses represent a major loss process in BHJ OPV devices. The $V_{\text {oc }}$ is inherently restricted due to the loss originating from the donor-acceptor electron transfer step ( $\Delta E_{\mathrm{LL}}$; Figure $1 b$ ). This could potentially be alleviated when applying high- $\varepsilon_{\mathrm{r}}$ materials. ${ }^{49}$ So et $a l$. investigated the dependence of the open-circuit voltage on the dielectric constant in more detail by dedicated experiments. ${ }^{50}$ Seven different active layer blends (based on PCDTBT, 
P3HT, PTB7, PDTS-TPD, PDTG-TPD, PDTB-TPD and PDTS-il) were explored and the dielectric constants of the photoactive layer blends were determined and correlated with the photovoltage loss due to the dielectric effect. The $\varepsilon_{r}$ values of the blends varied from $3.36 \pm$ 0.24 to $4.95 \pm 0.14$ and a clear correlation could be made with the energy loss in organic solar cells. A $V_{\text {oc }}$ loss of more than $0.3 \mathrm{~V}$ was observed for active layer blends with low dielectric constants in the range of 3-4, whereas these losses vanished for high- $\varepsilon_{r}(\sim 5)$ active layer blends. It was stated that organic donor materials should be designed with $\varepsilon_{r}$ values exceeding 6 to minimize the photovoltage losses due to the dielectric effect.

\section{- Cyano functionalization}

In 2014, the group of Jen reported a high dielectric constant for a PIDT-DPP polymer 23 (Figure 2) containing a cyano moiety at the outer ends of the DPP side chains. ${ }^{51}$ Preceding studies from the same group already showed that the incorporation of a $\mathrm{CN}$ group on the side chains does not really affect the hole mobility, frontier orbital energy levels and absorption profile. ${ }^{52}$ A dedicated device architecture was employed to eliminate possible interferences due to morphology, inherent to spin-coated BHJ polymer:fullerene blends. A non-conventional bilayer structure was used, wherein first the pure polymer $(30 \mathrm{~nm})$ was spin-coated and $C_{60}$ $(40 \mathrm{~nm})$ was deposited on top via thermal evaporation, followed by calcium and aluminum. The OPV device performance was investigated and an overall increase of all output parameters was reported for PIDT-DPP-CN 23, doubling the PCE (from 0.7 to 1.4\%) as compared to PIDT-DPP-alkyl 22 (Figure 2, Table 1). The dielectric properties of both polymers were investigated by impedance spectroscopy and $\varepsilon_{\mathrm{r}}$ values of 3.5 and 5.0 for $\mathbf{2 2}$ and 23, respectively, were obtained in the low frequency regime $\left(10^{3}-10^{6} \mathrm{~Hz}\right)$. Transient photovoltage (TPV) measurements done on both polymer solar cells showed suppression of the nongeminate charge recombination rates, which can be attributed to the dielectric constant increase. Because of the specific device architecture used and the similar opto-electrical material properties, it could be concluded that the observed increase in PCE can truly be attributed to the dielectric constant enhancement. This shows that there are definitely strong prospects for organic semiconductors with increased permittivities.

\section{- Other high- $\varepsilon_{\mathrm{r}}$ donor-type materials}

Mozer et al. studied the effect of bimolecular recombination for a high dielectric constant DPP-based polymer blended with $\mathrm{PC}_{61} \mathrm{BM} .{ }^{53}$ They found that the recombination coefficient was two times lower compared to a $\mathrm{P} 3 \mathrm{HT}: \mathrm{PC}_{61} \mathrm{BM}$ blend and one order of magnitude lower than in PCPDTBT:PC 61 BM. A smaller Coulomb capture radius was found for the DPP-based polymer blend, resulting in efficient charge extraction with active layers approaching $300 \mathrm{~nm}$, which is significantly thicker than most organic photoactive layers reported in literature. Remarkably, the authors did not apply any specific strategy to enhance the dielectric constant, but just used a regular alkylated DPP-based polymer $\mathbf{2 4}$ without polar(izable) substituents (Figure 2). Yet, they measured a very high $\varepsilon_{\mathrm{r}}$ of $16.7 \pm 0.4$ for the pure material and an $\varepsilon_{\mathrm{r}}$ of 7.3 \pm 0.75 for a $1: 3$ blend with $\mathrm{PC}_{61} \mathrm{BM}$ (at $1 \mathrm{kHz}$ ) by impedance and photo-CELIV (Table 1 ). For the pure materials, relatively low errors on the obtained $\varepsilon_{r}$ values were achieved, but the errors almost doubled for the blends. Moreover, batch to batch variations showed large differences for the blend dielectric constant, with a value varying from 4.5 to 7.3 despite the negligible 
difference in molar mass, dispersity, and impurity level (as judged by NMR) between the different polymer samples. The authors attribute the large difference in the blend dielectric constant to different film morphologies, affecting the domain size, crystallinity and phase purity. Yet, no further studies were performed to confirm this hypothesis. The reason for the very high dielectric constant compared to other analogous DPP-based low bandgap materials (e.g. compounds 12 and 13 ) also remains to be elucidated.

\subsection{High- $\varepsilon_{r}$ acceptor materials}

(Methano)fullerene derivatives ( $P C_{61} B M$ and $\left.P C_{71} B M\right)$ are still the most widely applied electron acceptor materials in OPV devices, although the field of non-fullerene OPV has recently developed at an impressive pace and similar (and even superior) performances can now be realized without fullerenes. ${ }^{12}$ Besides their relatively high cost, limited absorptivity and difficult structural fine-tuning, the standard fullerenes also show rather low dielectric constants ( $\sim$ for $\mathrm{PC}_{61} \mathrm{BM}$ ). Similar approaches as discussed above for the donor materials have hence been applied to fullerene compounds as well with the general aim to increase $\varepsilon_{r}$, although the efforts done remain limited to only three research groups. The structures of all acceptor materials discussed in this section are depicted in Figure 6 and the $\varepsilon_{r}$ values, reduction potentials, electron mobilities $\left(\mu_{\mathrm{e}}\right)$ and resulting OPV output parameters are listed in Table 2.

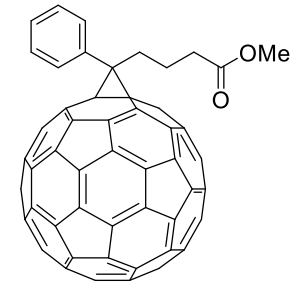

$25 \mathrm{PC}_{61} \mathrm{BM}$

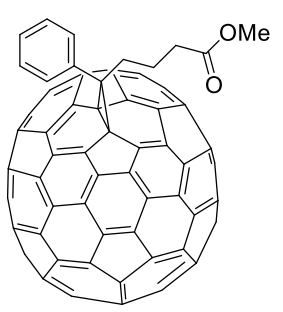

$26 \mathrm{PC}_{71} \mathrm{BM}$

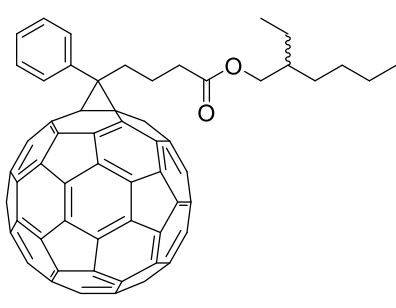

27 PCB-EH

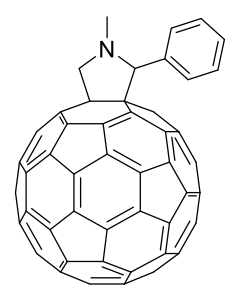

28 PP

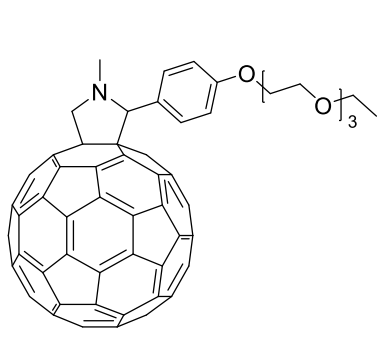

29 PTEG-1

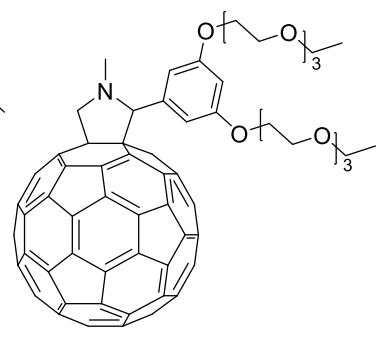

30 PTEG-2

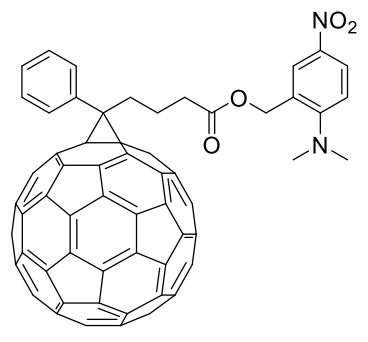

31 PCBDN

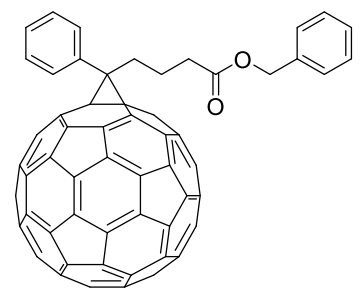

32 PCBBz

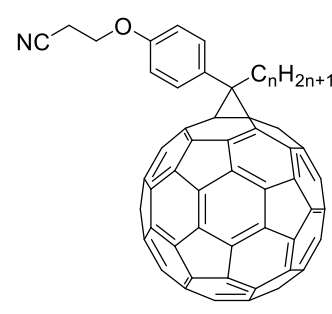

33 FCN-2: $n=2$ 34 FCN-4: $n=4$ 35 FCN $-6: n=6$ 36 FCN-8: $n=8$

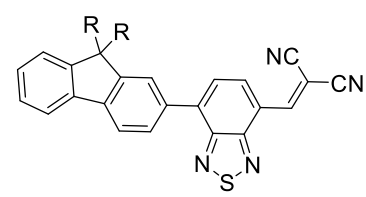

$37 \mathrm{~K} 12: \mathrm{R}=\mathrm{C}_{3} \mathrm{H}_{7}$ 38 M1: $\mathrm{R}=\mathrm{CH}_{2} \mathrm{OCH}_{2} \mathrm{CH}_{2} \mathrm{OCH}_{3}$

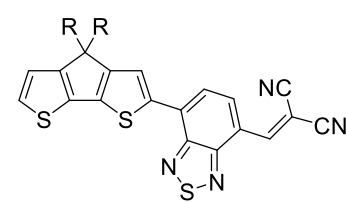

39 M2: $\mathrm{R}=\mathrm{CH}_{2} \mathrm{OCH}_{2} \mathrm{CH}_{2} \mathrm{OCH}_{3}$ $40 \mathrm{M3}: \mathrm{R}=\mathrm{C}_{8} \mathrm{H}_{17}$

Figure 6. Acceptor materials employed in $\varepsilon_{r}$ studies to improve the performance of organic solar cells. 
Table 2. Dielectric constants, reduction potentials and electron mobilities for acceptor materials employed in $\varepsilon_{r}$ studies and photovoltaic parameters of the resulting BHJ OPV devices.

\begin{tabular}{|c|c|c|c|c|c|c|c|c|c|c|}
\hline Compound & $\varepsilon_{r}$ & $\begin{array}{c}E_{1 / 2} 1, \\
\text { red }\end{array}$ & $\begin{array}{c}E_{1 / 2} 2, \\
\text { red }\end{array}$ & $\begin{array}{c}\mu_{\mathrm{e}}\left[\mathrm{cm}^{2}\right. \\
\left.V^{-} \mathrm{s}^{-}\right]^{\mathrm{b})}\end{array}$ & $\begin{array}{l}\text { Active layer } \\
\text { blend }\end{array}$ & $\begin{array}{c}J_{\mathrm{sc}} \\
{[\mathrm{mA}} \\
\left.\mathrm{cm}^{-2}\right]\end{array}$ & $\begin{array}{l}V_{\text {oc }} \\
{[\mathrm{V}]}\end{array}$ & $\mathrm{FF}$ & $\begin{array}{l}\text { PCE } \\
{[\%]^{c)}}\end{array}$ & Ref \\
\hline $\mathrm{PC}_{61} \mathrm{BM} 25$ & $\begin{array}{c}3.9 \pm \\
0.1\end{array}$ & -1.092 & -1.482 & $2 \times 10^{-3}$ & - & - & - & - & - & {$[30,54]$} \\
\hline PP 28 & $\begin{array}{c}3.6 \pm \\
0.4\end{array}$ & -1.114 & -1.508 & - & - & - & - & - & - & {$[30,54]$} \\
\hline PTEG-1 29 & $\begin{array}{c}5.7 \pm \\
0.2\end{array}$ & -1.113 & -1.511 & $2 \times 10^{-3}$ & - & - & - & - & - & {$[30,54]$} \\
\hline PTEG-2 30 & $\begin{array}{c}5.3 \pm \\
0.2\end{array}$ & -1.106 & -1.504 & $\begin{array}{c}3.5 \times \\
10^{-3}\end{array}$ & - & - & - & - & - & {$[29,54]$} \\
\hline PCBDN 31 & - & -1.089 & -1.482 & - & - & - & - & - & - & [55] \\
\hline PCBBz 32 & - & -1.095 & -1.489 & - & - & - & - & - & - & [55] \\
\hline FCN-2 33 & $\begin{array}{c}4.9 \pm \\
0.1\end{array}$ & $-0.95^{a)}$ & - & $\begin{array}{c}4.8 \times \\
10^{-3}\end{array}$ & PCDTBT:33 & 8.66 & 0.90 & 0.71 & 5.55 & [31] \\
\hline FCN-4 34 & $\begin{array}{c}4.9 \pm \\
0.1\end{array}$ & $-0.93^{a)}$ & - & $\begin{array}{c}4.4 \times \\
10^{-3}\end{array}$ & PCDTBT:34 & 8.54 & 0.88 & 0.46 & 3.43 & [31] \\
\hline FCN-6 35 & $\begin{array}{c}4.9 \pm \\
0.1\end{array}$ & $-0.95^{\text {a) }}$ & - & $\begin{array}{c}4.0 \times \\
10^{-3}\end{array}$ & PCDTBT:35 & 8.36 & 0.93 & 0.64 & 4.97 & [31] \\
\hline FCN-8 36 & $\begin{array}{c}4.9 \pm \\
0.1\end{array}$ & -0.94 a) & - & $\begin{array}{c}3.5 \times \\
10^{-3}\end{array}$ & PCDTBT:36 & 7.72 & 0.92 & 0.49 & 3.50 & [31] \\
\hline $\mathrm{PC}_{61} \mathrm{BM} 25$ & $\begin{array}{c}3.9 \pm \\
0.1\end{array}$ & -0.94 a) & - & $\begin{array}{c}2.1 \times \\
10^{-3}\end{array}$ & PCDTBT:25 & 7.73 & 0.91 & 0.65 & 4.56 & [31] \\
\hline K12 37 & 3.8 & -1.2 & - & $\begin{array}{c}5.0 \times \\
10^{-6}\end{array}$ & $\begin{array}{c}\text { P3HT:37 } \\
\text { P3HT:37 } \\
\text { (cryst) }\end{array}$ & $\begin{array}{l}0.22 \\
2.70\end{array}$ & $\begin{array}{l}0.70 \\
0.56\end{array}$ & $\begin{array}{l}0.25 \\
0.57\end{array}$ & $\begin{array}{l}0.04 \\
0.86\end{array}$ & [56] \\
\hline M1 38 & 8.5 & -1.3 & - & $\begin{array}{c}1.3 \times \\
10^{-6}\end{array}$ & РЗНТ:38 & 0.81 & 0.52 & 0.25 & 0.10 & [56] \\
\hline M2 39 & 9.8 & -1.2 & - & $\begin{array}{c}3.0 \times \\
10^{-6}\end{array}$ & Р3НТ:39 & 0.86 & 0.40 & 0.35 & 0.12 & [56] \\
\hline M3 40 & 4.3 & -1.1 & - & $\begin{array}{c}3.0 \times \\
10^{-7} \\
\end{array}$ & Р3НТ:40 & 0.51 & 0.38 & 0.35 & 0.07 & [56] \\
\hline
\end{tabular}

a) $E^{\text {red }}{ }_{\text {onset }}$ potentials. ${ }^{\text {b) }}$ Space-charge-limited current $(\mathrm{SCLC})$ mobility for the acceptor material. ${ }^{\text {c) }}$ Best efficiencies.

Hummelen, Koster and co-workers focused on the dielectric constant enhancement of fullerenes via the introduction of a TEG side chain. ${ }^{30,54}$ An increase from $3.6 \pm 0.4$ for the reference fullerene derivative PP 28 (without any side chains) to $5.7 \pm 0.2$ for PTEG-1 29 was observed (Figure 6), and this value was constant over a wide frequency range (from 100 to $10^{6}$ $\mathrm{Hz}$ ). Remarkably, further substitution of the fullerene derivative with a second TEG side chain slightly decreased the dielectric constant compared to PTEG-1. Based on this finding, the authors conclude that the increase of $\varepsilon_{r}$ is more complex than just increasing the amount of polar(izable) substituents. In this case, the interplay between the TEG side chains and the fullerene cage also plays a crucial role on the relative permittivity. The electron mobility of the fullerene derivatives did not significantly change, which is of great relevance for acceptor moieties since they efficiently need to transport the electrons to the cathode. Furthermore, the electro-optical properties were not devaluated by the introduction of ethylene glycol units and also the LUMO energy level remained similar. Moreover, strongly improved solubility was achieved in common organic solvents (e.g. chloroform, o-dichlorobenzene, ...). 
The Hummelen group recently also presented a promising strategy to improve charge separation by installing permanent dipoles in fullerene adducts (31 and $\mathbf{3 2}$; Figure 6). ${ }^{55}$ Although no dielectric constants were measured for the synthesized fullerene derivatives, enhanced dipole moments were calculated when specific functional groups were introduced to increase the electronic polarization. Modeling showed that addition of a certain amount of derivative $\mathbf{3 1}$ to the active layer blend facilitated charge separation in the proximity of the central donor-acceptor complex. Installing a permanent dipole is presented as a promising strategy, but further experiments need be done to illustrate this concept in $\mathrm{BHJ}$ organic solar cells.

Wang et al. recently reported on fullerene derivatives with 2-cyano-ethoxyphenyl side chains. ${ }^{31}$ The cyano-functionalized fullerenes (FCN-n 33-36; Figure 6) with different alkyl side chain lengths showed good solubility in common organic solvents (e.g. chloroform, chlorobenzene, toluene, ...) and improved thermal stabilities compared to $\mathrm{PC}_{61} \mathrm{BM}$. The optical and electrochemical properties were almost identical, whereas the electron mobilities of the novel fullerenes were slightly higher than the one of $\mathrm{PC}_{61} \mathrm{BM}$. Surface energies were found to be somewhat larger for the FCN- $n$ compounds, as expected because of the enhanced polarity, but still in the same range and therefore not disturbing the compatibility with the donor material PCDTBT. The dielectric constants were analyzed using impedance spectroscopy and all CN-functionalized fullerenes exhibited similar $\varepsilon_{r}$ values of $4.9 \pm 0.1$ (Table 2), considerably higher than $\mathrm{PC}_{61} \mathrm{BM}(3.9 \pm 0.1)$. These larger values can not only be attributed to the cyano moieties, but also to the ethylenoxy spacer, providing a higher degree of rotation along the side chain and a more easy response to an applied electric field. The photovoltaic performances of the novel fullerene adducts were evaluated in blends with PCDTBT and a maximum device efficiency of $5.55 \%$ was achieved for FCN-2 33 (compared to $4.56 \%$ for $\mathrm{PC}_{61} \mathrm{BM}$; Table 2). It should be mentioned that 2 out of the $4 \mathrm{FCN}-n$ fullerene derivatives performed less compared to $\mathrm{PC}_{61} \mathrm{BM}$, especially due to the significantly lower fill factors. Morphology studies were performed by means of TEM and AFM (atomic force microscopy) and, although higher surface energies were reported for the FCN- $n$ compounds, a finer fibrillar morphology was obtained for the best-performing device based on FCN-2 33 (Figure 7).
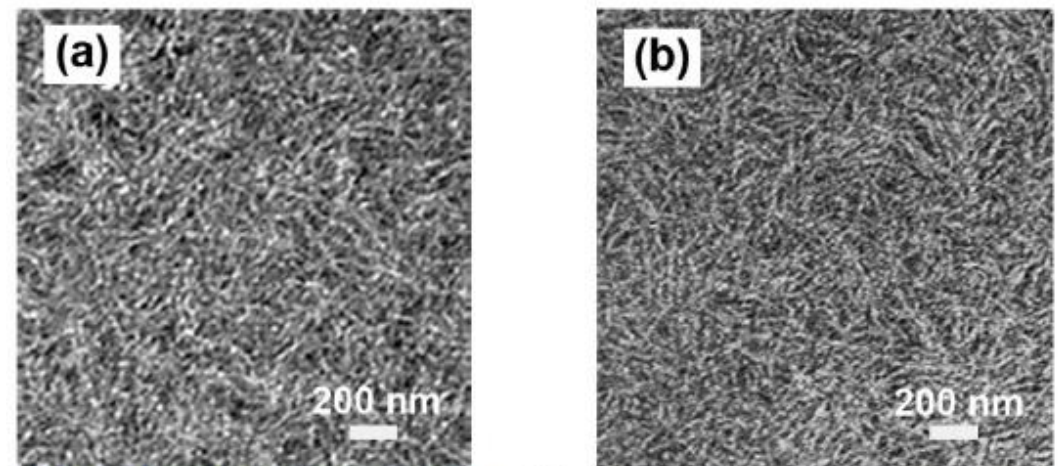

Figure 7. TEM images of the active layer blends containing a) PCDTBT:33 and b) PCDTBT:PC ${ }_{61} B M$. Reproduced with permission. ${ }^{31}$ Copyright 2016, Wiley.

The group of Burn and Meredith reported the first and so far only investigation on the dielectric constants of non-fullerene small molecule acceptors. ${ }^{56}$ They showed that the introduction of DEG side chains on either a fluorene or $4 H$-cyclopenta[2,1- $b: 3,4$ - 
$b^{\prime}$ ]dithiophene (CPDT) increased the static dielectric constant up to 8.5 for $\mathbf{3 8}$ and 9.8 for $\mathbf{3 9}$ (at $100 \mathrm{~Hz}$ ) (Figure 6, Table 2). The optical and electrochemical properties of the chromophores remained unaffected upon the DEG introduction, with reduction potentials similar to $\mathrm{PC}_{61} \mathrm{BM}$. The electron mobility of $\mathbf{3 8}$ was almost similar as compared to the alkylated reference compound, but for the CPDT based material 39 it improved with one order of magnitude upon the introduction of DEG. CELIV and impedance measurements showed that the glycolated compounds have larger static and low frequency dielectric constants, although the dielectric constants at high frequencies were slightly lower. Initial OPV tests were presented as well, combining the small molecule acceptors with $\mathrm{P} 3 \mathrm{HT}$, but rather low efficiencies were observed, up to $0.12 \%$ for the best performing device (Table 2 ). Slightly enhanced $J_{\mathrm{sc}}$ values compared to the hydrocarbon counterparts were obtained, but the differences are so small that other factors besides $\varepsilon_{r}$ (e.g. film morphology) can play a (more) decisive role.

\section{3. (In)organic additives to increase the blend $\varepsilon_{r}$}

Schmechel et al. investigated the effect of substrate permittivity on an organic semiconductor active layer. ${ }^{57}$ Different substrates with varying permittivities were used with pentacene as the photoactive material spin-coated on top. $\mathrm{SiO}_{2}, \mathrm{TiO}_{2}$ and $\mathrm{SrTiO}_{3}$ substrates were compared, with dielectric constants of 3.7, 88 and 305, respectively. The photo-charge carrier density ratio was investigated in dependence of the applied voltage and was found to increase with substrate permittivity. This can be attributed to the enhanced permittivity in the vicinity of the substrate-semiconductor interface, which results in a reduced Coulombic interaction and thereby facilitated charge separation and collection. Different active layer thicknesses were studied and, as expected, layer thicknesses up to the exciton diffusion length were most affected since all generated excitons can migrate to the organic-inorganic interface. This study suggested that introducing high- $\varepsilon_{r}$ (in)organic materials (dopants) in close proximity of the active layer could increase the photocurrent generation for organic photovoltaics. Moreover, it could be concluded that when a high permittivity inorganic material $\left(\varepsilon_{r}=300\right)$ comes in the neighborhood of an organic material, the electric field strength between the respective charges in the organic material is reduced by a factor of almost 2, while the electric field in the inorganic material is screened almost completely (Figure 8). Although this particular study focused merely on the substrate, it clearly shows the potential of high- $\varepsilon_{r}$ additives when blended in a photoactive layer. As a result, several attempts in this direction were taken by other groups, using various approaches.

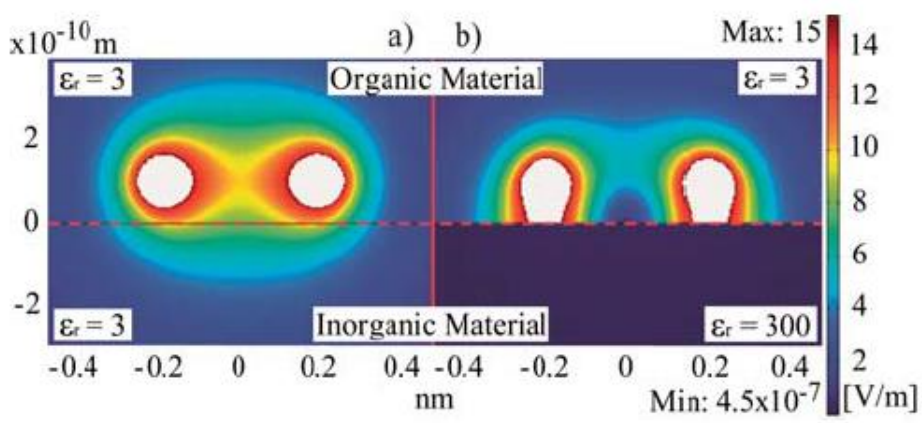


Figure 8. Electric field intensity between complementary point charges at an organic-inorganic interface, simulated by a finite element for (a) $\varepsilon_{r \text {,organic }}=\varepsilon_{r \text {,inorganic }}=3$ and (b) $\varepsilon_{r \text {,organic }}=3, \varepsilon_{r \text {,inorganic }}=300$. Reproduced with permission. ${ }^{57}$ Copyright 2012, Wiley.

In 2011, the group of Ginger reported results on charge generation and recombination in organic and hybrid solar cells. ${ }^{58}$ Different donor host materials were blended with organic acceptors ( $\left.\mathrm{PC}{ }_{61} \mathrm{BM}\right)$, inorganic acceptors $\left(\mathrm{ZnO}, \mathrm{TiO}_{2}\right)$ or colloidal quantum dots (PbS, CdSe). In general, longer average carrier lifetimes were measured in blends with inorganic acceptors compared to the $\mathrm{PC}_{61} \mathrm{BM}$ blends. The higher dielectric constants of the inorganic particles induce an increased dielectric screening of the photo-induced holes and electrons. The experimentally observed polaron lifetimes were also 10 times longer for the inorganic nanoparticles blends compared to different polymer: $\mathrm{PC}_{61} \mathrm{BM}$ blends.

Chaudhary et al. were the first to investigate the influence of a ferroelectric additive in the OPV active layer. They performed a study on P3HT:PC ${ }_{61} \mathrm{BM}$ doped with a high- $\varepsilon_{\mathrm{r}}(\sim 11)$ ferroelectric polymer PVDF-TrFE (41; Figure 9) to induce dipoles and to introduce a localized, increased electric field with the purpose to enhance charge dissociation. ${ }^{59} \mathrm{~A}$ PCE increase up to $50 \%$ was presented, with internal quantum efficiencies (IQE's) approaching $100 \%$, which represents a clear evidence that complete exciton dissociation at certain photon energies is achieved. An efficiency enhancement from 2.5 to 3.9\% was observed upon incorporation of $10 \%$ PVDF-TrFE in the blend, especially increasing the photocurrent and FF (Table 3). The rather low reference PCE was ascribed to the co-solvent (THF) needed to dissolve the additive. Although no dielectric constants were measured for the blend layers, the enhanced dissociation rate of the excitons was put forward as a main cause for the efficiency enhancement, which is inherently connected to the higher relative permittivity of the active layer.

In 2015, Chaudhary et al. also investigated the effects of the addition of $\mathrm{BaTiO}_{3}$ (BTO) nanoparticles to a $\mathrm{P} 3 \mathrm{HT}: \mathrm{PC}_{61} \mathrm{BM}$ active layer to increase the exciton dissociation and light scattering. ${ }^{60}$ The BTO particles were functionalized (f-BTO) with methyl-terminated agents via a silanization process in which the surface hydroxyl groups were converted with the aid of $p$ tolyltrimethoxysilane to prevent precipitation of the particles. Addition of $5 \mathrm{wt} \%$ methylterminated BTO afforded a large increase (40\%) in $J_{\text {sc }}$ when the photoactive layer was spincoated outside the glovebox, which was mainly done to enable immediate use of the solutions after sonication (Table 3). Solar cell fabrication in an inert atmosphere led to overall more efficient devices, but, remarkably, almost no effect of the f-BTO addition was observed (Table 3). The density of trap states was investigated and revealed an increase of trap states when $\mathrm{f}$ BTO particles were added to the active layer, which increases recombination instead of reducing it, despite the (potentially) higher dielectric constant. Simulations with the exciton drift-diffusion model also demonstrated that the bare nanoparticles enhance exciton dissociation, while the methyl termination could cancel this effect. This suggests that the fBTO nanoparticles can enhance the OPV characteristics because of light scattering rather than improved charge dissociation. 


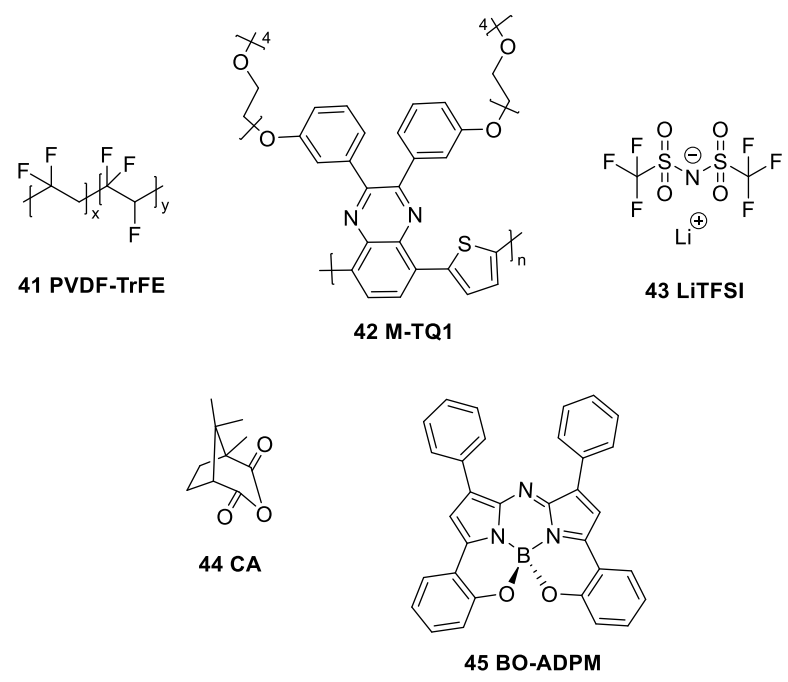

Figure 9. High- $\varepsilon_{r}$ additives and host materials for BHJ organic/hybrid solar cells.

Table 3. Photovoltaic parameters for BHJ OPV devices prepared from high- $\varepsilon_{r}$ dopants added to the photoactive layer.

\begin{tabular}{|c|c|c|c|c|c|c|c|}
\hline Compound & $\varepsilon_{\mathrm{r}}$ & $\begin{array}{c}\text { Active layer } \\
\text { blend }\end{array}$ & $\begin{array}{c}J_{\mathrm{sc}} \\
{\left[\mathrm{mA} \mathrm{cm}^{-2}\right]}\end{array}$ & $\begin{array}{l}V_{\text {oc }} \\
{[\mathrm{V}]}\end{array}$ & $\mathbf{F F}$ & $\begin{array}{l}\text { PCE } \\
{[\%]^{c)}}\end{array}$ & Ref \\
\hline 41 & & $\begin{array}{c}\mathrm{P} 3 \mathrm{HT}: \mathrm{PC}_{61} \mathrm{BM}+ \\
0 \% 41\end{array}$ & 9.6 & 0.55 & 0.48 & 2.5 & [59] \\
\hline 41 & 11 & $\begin{array}{c}\text { P3HT:PC }{ }_{61} B M+ \\
10 \% 41\end{array}$ & 11.3 & 0.57 & 0.60 & 3.9 & [59] \\
\hline f-BTO & - & $\begin{array}{c}\text { P3HT:PC } 61 \text { BM + } \\
0 \% \text { f-BTO (air) }\end{array}$ & 5.13 & 0.59 & 0.62 & 1.87 & {$[60]$} \\
\hline f-BTO & - & $\begin{array}{c}\text { P3HT:PC } 61 \text { BM + } \\
5 \% \text { f-BTO (air) }\end{array}$ & 7.21 & 0.60 & 0.63 & 2.72 & {$[60]$} \\
\hline f-BTO & - & $\begin{array}{c}\text { P3HT:PC } 61 \text { BM + } \\
0 \% \text { f-BTO }\left(\mathrm{N}_{2}\right)\end{array}$ & 9.30 & 0.61 & 0.55 & 3.08 & {$[60]$} \\
\hline f-BTO & - & $\begin{array}{c}\text { P3HT:PC } 61 \text { BM + } \\
5 \% \text { f-BTO }\left(\mathrm{N}_{2}\right)\end{array}$ & 9.88 & 0.61 & 0.51 & 3.07 & {$[60]$} \\
\hline 42 & $\begin{array}{c}5.1 \pm \\
0.3\end{array}$ & M-TQ1:PC $61 B M$ & $\sim 2.2$ a) & $\sim 0.76^{\text {a) }}$ & $\sim 0.62$ a) & $\sim 1.1^{\text {a) }}$ & {$[61]$} \\
\hline $\begin{array}{c}42+43 \\
\left(0.015 \mathrm{Li}^{+} / \mathrm{O}\right)\end{array}$ & $\begin{array}{c}145 \pm \\
20\end{array}$ & $\begin{array}{l}\text { M-TQ1:PC } 61 \mathrm{BM} \\
\quad+0.01 \mathrm{Li}^{+} / \mathrm{O}\end{array}$ & $\sim 2.5^{\text {a) }}$ & $\sim 0.62$ a) & $\sim 0.55^{\text {a) }}$ & $\sim 0.8$ a) & {$[61]$} \\
\hline 45 & 4.5 & bilayer with $\mathrm{C}_{60}$ & 4.65 & 0.55 & 0.53 & 1.34 & {$[62]$} \\
\hline $\begin{array}{c}44: 45 \\
(30: 70)\end{array}$ & 8 & bilayer with $\mathrm{C}_{60}$ & 4.95 & 0.62 & 0.56 & 1.72 & {$[62]$} \\
\hline $\begin{array}{c}44: 45 \\
(50: 50)\end{array}$ & 10.8 & bilayer with $\mathrm{C}_{60}$ & 4.41 & 0.65 & 0.50 & 1.43 & {$[62]$} \\
\hline 1 & $\sim 4.7^{a, b)}$ & $\begin{array}{c}\text { MDMO- } \\
\text { PPV:PC }{ }_{61} B M\end{array}$ & $\sim 1.45^{\text {a) }}$ & $\sim 0.90$ a) & $\sim 0.29$ a) & $\sim 0.38$ a) & [63] \\
\hline $\begin{array}{c}\text { MDMO- } \\
\text { PPV:PC } 61 \text { BM } \\
+10 \% 44\end{array}$ & $\sim 6.1^{\mathrm{a}, \mathrm{b})}$ & $\begin{array}{c}\text { MDMO- } \\
\text { PPV:PC } 61 \text { BM + } \\
20 \% 44\end{array}$ & $\sim 2.0^{\text {a) }}$ & $\sim 0.89$ a) & $\sim 0.35^{\text {a) }}$ & $\sim 0.63^{\text {a) }}$ & [63] \\
\hline
\end{tabular}

a) Estimated values deduced from figures as no exact values were reported. b) Blend dielectric constants. ${ }^{c)}$ Average efficiencies.

The group of Asbury reported an increased density of holes and a higher static dielectric permittivity of a polymer blend via salt doping. ${ }^{61}$ Lithium bis(trifluoromethylsulfonyl)imide (LiTFSI) was added to a quinoxaline-based low bandgap polymer M-TQ1 (42; Figure 9) to 
increase the dielectric properties of the blend photoactive layer. The conjugated polymer was functionalized with long tetra(ethylene glycol) side chains to chelate small cations, permitting dispersal of salt ion pairs in the polymer phase. Dielectric constant measurements by means of impedance spectroscopy revealed an $\varepsilon_{r}$ of $5.1 \pm 0.3$ in the range of $\mathrm{Hz}$ to $\mathrm{MHz}$ for the pure polymer without the addition of LiTFSI, while a very large increase up to $145 \pm 20$ was reported when the polymer was doped with a $0.015 \mathrm{Li} / 0$ ratio (Table 3 ). It should, however, be noted that a steep decrease in $\varepsilon_{r}$ was observed at low frequencies $(10-100 \mathrm{~Hz})$. Since the influence on the high frequency regime is minimal, exciton dissociation in BHJ OPV devices will not largely be influenced because bimolecular recombination occurs at a $\mu$ s timescale. This was confirmed when making OPV devices (Table 3). The addition of LiTFSI did not result in improved device parameters and the final devices even performed a bit worse.

A different strategy was employed by Ma et al. ${ }^{62}$ They blended an organic small molecule additive, camphoric anhydride (CA 44; Figure 9), in a B,O-chelated azadipyrromethene donor material (BO-ADPM 45; Figure 9), selected because of its broad absorption spectrum up to the near-infrared, to increase the film relative permittivity. The small molecule addition to the pristine donor film more than doubled the dielectric constant, from $\sim 4.5$ to $\sim 11$, with reduced exciton binding energies and an improved IQE. The relative permittivity of the film linearly increased from 4.5 to 10.8 upon the addition of CA up to $50 \mathrm{wt} \%$, but this goes hand in hand with a significant drop in film absorption properties because CA does not absorb in the visible region. Bilayer solar cell devices were investigated using $C_{60}$ as the acceptor layer. Despite the clear enhancement in IQE, no significant increase of the short-circuit current was observed (Table 3). The increase in IQE is probably counteracted by the lower hole mobilities (from $\sim 10^{-}$ ${ }^{5}$ to $\sim 10^{-7} \mathrm{~cm}^{2} / \mathrm{Vs}$ ) observed upon increasing the amount of CA. On the other hand, an increase in $V_{\text {oc }}$ from 0.55 to 0.65 was seen when going to a 1:1 BO-ADPM:CA blend, which was attributed to the increase in dipole moment at the interface between BO-ADPM:CA and $C_{60}$.

Further studies by the same group employing CA as an additive for a different system, i.e. MDMO-PPV:PC 61 BM, again showed an increased film relative permittivity with reduced $C T$ state energy. In this case, a PCE increase was achieved by the addition of $20 \mathrm{wt} \% \mathrm{CA}$, although the efficiency remained very low ( $0.6 \%$, Table 3$).{ }^{63}$ Improved dielectric constants, from $\sim 4.7$ to $\sim 6$, were obtained by the addition of $10 \mathrm{wt} \%$ of $C A$, while further increasing the amount of CA led to a drop in $\varepsilon_{\text {r. }}$ In contrast to the previous study, an increase in $J_{\text {sc }}$ and FF was seen going from 0 to $20 \mathrm{wt} \% \mathrm{CA}$, whereas the $V_{\text {oc }}$ slightly decreased (Table 3). The drop in $V_{\text {oc }}$ was attributed to the reduced energy of the CT state. AFM analysis showed that more and larger separate domains were formed upon the addition of CA. This indicates that CA does phase separate when too much of it is added, which is detrimental for the photovoltaic performance.

\section{Conclusions and outlook}

Over the past 10 years, only a limited number of studies have been devoted to the enhancement of the dielectric properties of organic semiconducting materials developed for organic photovoltaics, as outlined in more detail above. Different functionalities (e.g. (oligo)ethylene glycol, fluoro and cyano) were introduced on the backbone or periphery of electron donor type conjugated polymers with the aim to increase the polarizability and relative permittivity of the resulting bulk heterojunction blends. Addition of oligo(ethylene 
glycol) side chains is the most widely used approach. As the polymer backbone remains unaffected, the dielectric constants can be increased without significantly altering the charge carrier mobilities. The enhanced $\varepsilon_{r}$ values result from the larger dipole moment of the $\mathrm{C}-\mathrm{O}$ units and the higher degree of flexibility, enabling a fast response to an applied electric field. This increased flexibility also induces a closer $\pi-\pi$ stacking of the polymer chains. ${ }^{64}$ In most cases, increased HOMO energy levels are observed due to the electron-donating ability of the glycol side chains, which has a negative impact on the open-circuit voltage. In this respect, fluorination is more beneficial, as it allows simultaneous improvement of the dielectric properties and the $V_{\text {oc. }}$. On the electron acceptor side, most studies focused on fullerene materials and very similar structural modifications (i.e. mainly introduction of short glycol chains) have been made to increase $\varepsilon_{r}$. Only one single report mentions non-fullerene electron acceptors. ${ }^{56}$ In a totally different way of working, dopants with very high permittivities were added to the photoactive layer.

When analyzing the available literature more critically, a few important observations can be made, which can serve as guidelines for future work in the field:

(i) Very limited structural variations, as well in the active materials as the substituents employed to enhance $\varepsilon_{r}$, have been applied so far to establish structure - dielectric constant-device efficiency relationships. As such, there is certainly plenty of room for improvement. Lots of questions remain on which structural modifications are most beneficial to enhance the dielectric constant. On the other hand, the conjugated polymer backbones have also shown quite some variations in $\varepsilon_{\mathrm{r}}$ and also in this respect more research is needed to understand these differences. Furthermore, no dielectric constants were determined for the state of the art highperformance OPV materials (electron donors and acceptors). It would be good to obtain these values and to test the approaches to (further) enhance $\varepsilon_{r}$ on these materials.

(ii) Although enhanced permittivities were obtained in multiple cases, this did not automatically result in better solar cell performances. The increased polarity of the functionalized materials often led to compatibility issues in the active layer blend. In general, studies were done on either the electron donor or acceptor material, whereas simultaneous efforts on both classes of compounds are needed to adjust their polarities, surface energies and miscibility. Eventually, when very high dielectric constant materials can be achieved, homojunction (i.e. single layer) organic devices could be realized - which was the initial goal for setting up high- $\varepsilon_{\mathrm{r}}$ studies $^{23}$ - and miscibility issues would be inherently resolved.

(iii) Also when adding dielectric dopants with very high $\varepsilon_{r}$ values, minor effects have usually been observed. This can be attributed to the very large interface surface, inducing trap states and thereby counteracting the enhanced dielectric constants. Especially the strong interfacial polarization (Maxwell-Wagner effect) results in a strong dispersion of $\varepsilon_{\mathrm{r} .}{ }^{65}$ Introducing a third phase in ternary blends may also affect other properties and high dielectric losses were observed. On the other hand, the large surface energies and interface areas can also induce more light scattering in the blend and thereby enhance light absorption. 
(iv) The higher hydrophilicity of most high- $\varepsilon_{r}$ organic semiconductors enables processing from more environmentally benign, non-halogenated solvents (e.g. alcohols). Despite the high importance of 'green' processing for future OPV commercialization, this aspect has been undervalued so far.

(v) Non-fullerene acceptors have recently afforded record device performances comparable to and even outperforming those achieved with fullerene-based OPV blends. ${ }^{12}$ Also for the purpose of dielectric constant enhancement, non-fullerene acceptors give new possibilities. More structural variations are possible because of the different suitable backbones (ITIC, perylene diimides, ...) ${ }^{66}$ and the ease to introduce polar/polarizable units on various locations.

(vi) Different strategies have been applied to measure the dielectric constants (impedance or CELIV) using diverse device stacks (e.g. $\mathrm{SiO}_{2}$ or glass substrates, different electric contacts, ...) and making certain assumptions, complicating straightforward comparison of the obtained values. In a few cases, the employed technique is even not mentioned. Furthermore, almost no active layer (blend or pristine material) roughness data have been reported, although significant errors can be made when rough, non-uniform layers are used for the measurements. Only a few groups report error bars on the $\varepsilon_{\mathrm{r}}$ measurements. As a result, there are doubts on the interpretation of certain literature values, which is obviously hindering further progress. A unified, standard protocol for the determination of $\varepsilon_{r}$ should therefore be defined to achieve reliable dielectric constants and to draw proper conclusions on structure - dielectric constant - device efficiency trends. This will most certainly give a new impetus to the field and attract other researchers to the remaining challenges to exploit the full potential of high dielectric constant conjugated materials for organic photovoltaics (and organic electronics in general).

\section{Conflicts of interest}

There are no conflicts of interest to declare.

\section{Acknowledgements}

This work was supported by the Research Foundation - Flanders (FWO Vlaanderen) (projects G.0415.14N and G.0B67.15N). J. Brebels acknowledges the former Agency for Innovation by Science and Technology in Flanders (IWT; now FWO Strategic Basic Research) for his PhD grant. 


\section{References}

1 G. Dennler, M. C. Scharber and C. J. Brabec, Adv. Mater., 2009, 21, 1323.

2 M. Kaltenbrunner, M. S. White, E. D. Głowacki, T. Sekitani, T. Someya, N. S. Sariciftci and S. Bauer, Nat. Commun., 2012, 3, 770.

3 Y. W. Su, S. C. Lan and K. H. Wei, Mater. Today, 2012, 15, 554.

4 L. Dou, J. You, Z. Hong, Z. Xu, G. Li, R. A. Street and Y. Yang, Adv. Mater., 2013, 25, 6642.

5 K. A. Mazzio and C. K. Luscombe, Chem. Soc. Rev., 2015, 44, 78.

6 S. B. Darling and F. You, RSC Adv., 2013, 3, 17633.

7 S. Lizin, S. Van Passel, E. De Schepper, W. Maes, L. Lutsen, J. Manca and D. Vanderzande, Energy Environ. Sci., 2013, 6, 3136.

8 H. Kang, G. Kim, J. Kim, S. Kwon, H. Kim and K. Lee, Adv. Mater., 2016, 28, 7821.

9 K. Müllen and W. Pisula, J. Am. Chem. Soc., 2015, 137, 9503.

10 S. Holliday, Y. Li and C. K. Luscombe, Prog. Polym. Sci., 2017, 70, 34.

11 J. Zhao, Y. Li, G. Yang, K. Jiang, H. Lin, H. Ade, W. Ma and H. Yan, Nat. Energy, 2016, 1, 15027.

12 W. C. Zhao, S. Li, H. Yao, S. Zhang, Y. Zhang, B. Yang and J. Hou, J. Am. Chem. Soc., 2017, 139, 7148.

13 C. J. Brabec, N. S. Sariciftci and J. C. Hummelen, Adv. Funct. Mater., 2001, 11, 15.

14 M. Knupfer, Appl. Phys. A, 2003, 77, 623.

15 M. Hiramoto, H. Fujiwara and M. Yokoyama, Appl. Phys. Lett., 1991, 58, 1062.

16 G. Yu, J. Gao, J. C. Hummelen, F. Wudl and A. J. Heeger, Science, 1995, 270, 1789.

17 J. J. M. Halls, C. A. Walsh, N. C. Greenham, E. A. Marseglia, R. H. Friend, S. C. Moratti and A. B. Holmes, Nature, 1995, 376, 498.

18 S. H. Park, A. Roy, S. Beaupré, S. Cho, N. Coates, J. S. Moon, D. Moses, M. Leclerc, K. Lee and A. J. Heeger, Nature Photon., 2009, 3, 297.

19 J. J. Van Franeker, M. Turbiez, W. Li, M. M. Wienk and R. A. J. Janssen, Nat. Commun., 2015, 6, 6229 .

20 M. C. Scharber, D. Mühlbacher, M. Koppe, P. Denk, C. Waldauf, A. J. Heeger and C. J. Brabec, Adv. Mater., 2006, 18, 789.

$21 \mathrm{H}$. Zhou, L. Yang and W. You, Macromolecules, 2012, 45, 607.

22 R. L. Uy, S. C. Price and W. You, Macromol. Rapid Commun., 2012, 33, 1162.

23 L. J. A. Koster, S. E. Shaheen and J. C. Hummelen, Adv. Energy Mater., 2012, 2, 1246.

24 T. Kirchartz, K. Taretto and U. Rau, J. Phys. Chem. C, 2009, 113, 17958.

25 A. S. Davydov, Theory of Molecular Excitons; Plenum: New York, 1971.

26 T. M. Clarke and J. R. Durrant, Chem. Rev., 2010, 110, 6736.

27 M. Lenes, L. J. A. Koster, V. D. Mihailetchi and P. W. M. Blom, Appl. Phys. Lett., 2006, 88, 243502.

28 N. Camaioni and R. Po, J. Phys. Chem. Lett., 2013, 4, 1821.

29 M. L. I. Ibrahim, Z. Ahmad, K. Sulaiman and S. V. Muniandy, AIP Adv., 2014, 4, 057133.

30 S. Torabi, F. Jahani, I. Van Severen, C. Kanimozhi, S. Patil, R. W. A. Havenith, R. C. Chiechi, L. Lutsen, D. J. M. Vanderzande, T. J. Cleij, J. C. Hummelen and L. J. A. Koster, Adv. Funct. Mater., 2015, 25, 150.

31 S. Zhang, Z. Zhang, J. Liu and L. Wang, Adv. Funct. Mater., 2016, 26, 6107. 
32 Y. Galagan, I. G. de Vries, A. P. Langen, R. Andriessen, W. J. H. Verhees, S. C. Veenstra and J. M. Kroon, Chem. Eng. Process, 2011, 50, 454.

33 J. G. Tait, T. Merckx, W. Li, C. Wong, R. Gehlhaar, D. Cheyns, M. Turbiez and P. Heremans, Adv. Funct. Mater., 2015, 25, 3393.

34 S. Zhang, L. Ye, H. Zhang and J. Hou, Mater. Today, 2016, 19, 533.

35 Y. Yao, J. Hou, Z. Xu, G. Li and Y. Yang, Adv. Funct. Mater., 2008, 18, 1783.

36 Y. Chen, S. Zhang, Y. Wu and J. Hou, Adv. Mater., 2014, 26, 2744.

37 T. R. Andersen, T. T. Larsen-Olsen, B. Andreasen, A. P. L. Böttiger, J. E. Carlé, M. Helgesen, E. Bundgaard, K. Norrman, J. W. Andreasen, J. W. Jorgensen and F. C. Krebs, ACS Nano, 2011, 5, 4188.

38 M. Breselge, I. Van Severen, L. Lutsen, P. Adriaensens, J. Manca, D. Vanderzande and T. Cleij, Thin Solid Films, 2006, 511-512, 328.

39 M. Lenes, F. B. Kooistra, J. C. Hummelen, I. Van Severen, L. Lutsen, D. Vanderzande, T. J. Cleij and P. W. M. Blom, J. Appl. Phys., 2008, 104, 114517.

40 W.-H. Chang, J. G. Gao, L. Dou, C.-C. Chen, Y. Liu and Y. Yang, Adv. Energy Mater., 2014, 4, 1300864.

41 X. Chen, Z. Zhang, Z. Ding, J. Liu and L. Wang, Angew. Chem. Int. Ed., 2016, 55, 10376.

42 J. C. Bijleveld, A. P. Zoombelt, S. G. J. Mathijssen, M. M. Wienk, M. Turbiez, D. M. de Leeuw and R. A. J. Janssen, J. Am. Chem. Soc., 2009, 131, 16616.

43 B. Meng, H. Y. Song, X. X. Chen, Z. Y. Xie, J. Liu and L. X. Wang, Macromolecules, 2015, 48, 4357.

44 Y. Lu, Z. Xiao, Y. Yuan, H. Wu, Z. An, Y. Hou, C. Gao and J. Huang, J. Mater. Chem. C, 2013, 1,630 .

45 H.-Y. Chen, J. Hou, S. Zhang, Y. Liang, G. Yang, Y. Yang, L. Yu, Y. Wu and G. Li, Nat. Photonics, 2009, 3, 649.

46 P. Verstappen, J. Kesters, W. Vanormelingen, G. Heintges, J. Drijkoningen, T. Vangerven, L. Marin, S. Koudjina, B. Champagne, J. Manca, L. Lutsen, D. Vanderzande and W. Maes, J. Mater. Chem. A, 2015, 3, 2960.

47 P. Yang, M. Yuan, D. F. Zeigler, S. E. Watkins, J. A. Lee and C. K. Luscombe, J. Mater. Chem. C, 2014, 2, 3278.

48 K. Vandewal, A. Gadisa, W. D. Oosterbaan, S. Bertho, F. Banishoeib, I. Van Severen, L. Lutsen, T. J. Cleij, D. Vanderzande and J. V. Manca, Adv. Funct. Mater., 2008, 18, 2064.

49 S. Kraner, R. Scholz, C. Koerner and K. Leo, J. Phys. Chem. C, 2015, 119, 22820.

50 S. Chen, S.-W. Tsang, T.-H. Lai, R. Reynolds and F. So, Adv. Mater., 2014, 26, 6125.

51 N. Cho, C. W. Schlenker, K. M. Knesting, P. Koelsch, H. L. Yip, D. S. Ginger and A. K. Y. Jen, Adv. Energy Mater., 2014, 4, 1301857.

52 Y. Sun, S. C. Chien, H. L. Yip, K. S. Chen, Y. Zhang, J. A. Davies, F. C. Chen, B. Lin and A. K. Y. Jen, J. Mater. Chem., 2012, 22, 5587.

53 G. Zhang, T. M. Clarke and A. J. Mozer, J. Phys. Chem. C, 2016, 120, 7033.

54 F. Jahani, S. Torabi, R. C. Chiechi, L. J. A. Koster and J. C. Hummelen, Chem. Commun., 2014, 50, 10645.

55 H. D. De Gier, F. Jahani, R. Broer, J. C. Hummelen and R. W. A. Havenith, J. Phys. Chem. A, 2016, 120, 4664.

56 J. E. Donaghey, A. Armin, P. L. Burn and P. Meredith, Chem. Commun., 2015, 51, 14115. 
57 M. Engel, F. Kunze, D. C. Lupascu, N. Benson and R. Schmechel, Phys. Status Solidi RRL, $2012,6,68$.

58 K. M. Noone, S. Subramaniyan, Q. Zhang, G. Cao, S. A. Jenekhe and D. S. Ginger, J. Phys. Chem. C, 2011, 115, 24403.

59 K. S. Nalwa, J. A. Carr, R. C. Mahadevapuram, H. K. Kodali, S. Bose, Y. Chen, J. W. Petrich, B. Ganapathysubramanian and S. Chaudhary, Energy Environ. Sci., 2012, 5, 7042.

60 R. S. Gebhardt, P. Du, A. Peer, M. Rock, M. R. Kessler, R. Biswas, B. Ganapathysubramanian and S. Chaudhary, J. Phys. Chem. C, 2015, 119, 23883.

61 X. Liu, K. S. Jeong, B. P. Williams, K. Vakhshouri, C. Guo, K. Han, E. D. Gomez, Q. Wang and J. B. Asbury, J. Phys. Chem. B, 2013, 117, 15866.

62 S. Y. Leblebici, T. L. Chen, P. Olalde-Velasco, W. Yang and B. Ma, ACS Appl. Mater. Interfaces, 2013, 5, 10105.

63 S. Leblebici, J. Lee, A. Weber-Bargioni and B. Ma, J. Phys. Chem. C, 2017, 121, 3279.

64 R. Boese, H. C. Weiss and D. Bläser, Angew. Chem. Int. Ed., 1999, 38, 988.

65 C. P. Smyth, Dielectric Behavior and Structure: Dielectric Constant and Loss, Dipole Moment and Molecular Structure. McGraw-Hill Book Company, New York, 1955.

66 S. Li, Z. Zhang, M. Shi, C.-Z. Li and H. Chen, Phys. Chem. Chem. Phys., 2017, 19, 3440. 